\title{
Single-tank thermal energy storage systems for concentrated solar power: Flow distribution optimization for thermocline evolution management
}

\author{
Wanruo LOUa, Yilin FANa, Lingai LUOa* \\ a Université de Nantes, CNRS, Laboratoire de thermique et énergie de Nantes, LTeN, UMR 6607, F- \\ 44000 Nantes, France
}

\begin{abstract}
Concentrated Solar Power (CSP) technology captures solar radiation and converts it into heat for electricity production. It has received an increasing attention because integrated thermal energy storage (TES) systems can largely enhancing the reliability and the dispatchability. Over the last decade, low-cost single storage tank based on the thermocline technology becomes an alternative to commonly-used two-tank TES system. However, the improper inlet/outlet manifolds may cause the strong mixing of hot and cold fluids and disturb the temperature stratification, resulting in reduced thermal performances of the storage tank.
\end{abstract}

This study aims at solving the flow maldistribution problem in the single-tank thermocline storage system by appropriately structuring the inlet/outlet manifolds. The technical solution is based on the insertion of optimized perforated baffles in the manifolds. 2D Computational fluid dynamics simulations were performed to calculate the transient flow and temperature profiles in the storage tank during the charging and discharging operations. The optimal size distribution of orifices on the upper baffle has been determined for homogenizing passage times of the thermal front, so as to enhance the temperature stratification. A novel intermediate evaluation indicator was introduced to characterize the real-time thermal behavior, which could reduce the computational cost of the optimization problem by a factor of 6 at least. Numerical results shown that the proposed optimization algorithm could significantly improve the thermal performances, indicated by the increased values of charging/discharging efficiency, the capacity ratio and the overall efficiency, ex., the fully charging efficiency be increased by $29 \%$ by comparing the unstructured manifold geometry and the one with optimized baffles. The parametric study on certain geometry and operating factors also demonstrated that the proposed method for flow distribution optimization was robust, effective and efficient.

Keywords: Concentrated Solar Power (CSP); Thermal Energy Storage (TES); Temperature stratification; Thermocline evolution; Thermal front; Flow distribution

*Corresponding author. Tel.: +33 240683 I67; E-mail address: lingai.luo@univ-nantes.fr 
$6 \quad E$

$7 e$

$8 H$

$9 h$

$10 \quad L$

$11 l$

$12 \dot{m}$

$13 N$

$14 P$

15 Re

$16 S$

$17 S^{*}$

$18 T$

$19 T^{*}$

$20 t$

$21 t^{*}$

$22 \quad \overline{t^{*}}$

$23 v$

$24 \quad v^{*}$

$25 \quad \bar{v}$

$26 \quad W$

$27 \quad X$

$28 X^{*}$

$29 \quad Y$

30

31

$\alpha$
Heat capacity at constant pressure $\left[\mathrm{J} \mathrm{kg}^{-1} \mathrm{~K}^{-1}\right]$

Size of orifice [m]

Energy [J]

Thickness [m]

Height of thermocline tank [m]

Height of the middle flow zone [m]

Length of tank [m]

Size of upper/bottom manifolds [m]

Mass flow rate $\left[\mathrm{kg} \mathrm{s}^{-1}\right]$

Number of orifice [-]

Position of horizontal cutting-section [-]

Reynolds number [-]

Surface area $\left[\mathrm{m}^{2}\right]$

Dimensionless surface area of thermocline zone [-]

Temperature [K]

Dimensionless temperature [-]

Time [s]

Dimensionless time [-]

Dimensionless mean value of all passage times [-]

Velocity [ $\left.\mathrm{m} \mathrm{s}^{-1}\right]$

Dimensionless velocity [-]

Mean velocity $\left[\mathrm{m} \mathrm{s}^{-1}\right]$

Port size [m]

$X$-coordinate $[\mathrm{m}]$

Dimensionless $X$-coordinate [-]

$Y$-coordinate $[\mathrm{m}]$

\section{Greek symbols}

Proportion of orifice size [-]

Relaxation factor [-]

Tail factor [-]

Efficiency [-]

Cone angle $\left[^{\circ}\right]$

Thermal conductivity [ $\left.\mathrm{W} \mathrm{m}^{-1} \mathrm{~K}^{-1}\right]$

Viscosity $\left[\mathrm{kg} \mathrm{m}^{-1} \mathrm{~s}^{-1}\right]$

Density $\left[\mathrm{kg} \mathrm{m}^{-3}\right]$

Capacity ratio [-]

Global porosity of baffle [-] 
1 Subscripts/superscripts

2 ch

Charging

3 dis

Discharging

$4 \quad f$

End moment for fully charging/discharging

5 Fin

Intermediate stop moment

$6 \quad H$

High temperature

$7 \quad i$

Orifice index

8 in

Inlet

9 ideal

Ideal case

$10 j$

Optimization step

$11 L$

Low temperature

$12 \max$

Maximum

13 out

Outlet

14 overall

Overall charging-discharging process

15 port

Inlet/outlet port

16 stored

Stored

17 tank

Thermocline-based TES tank

18 tot

Total void fluid area

19 unit

Unit of baffle

$20 x$

Threshold coefficient [-]

210

Initial state

22

23

Abbreviations

24

CFD

Computational Fluid Dynamics

25 CSP

Concentrated solar power

26 GHG

Greenhouse gas

27 HTF

Heat transfer fluid

28 TES

Thermal energy storage

29 STD

Standard derivation 


\section{Introduction}

Nowadays, the increasing energy consumption worldwide, the higher price of fossil fuels and the environmental impacts of greenhouse gas (GHG) emission stimulate the use of renewable resources as the alternative [Nicolas et al., 2019]. Solar energy conversion by Concentrated Solar Power (CSP) technology has a great potential within the future energy scenario because the integrated thermal energy storage (TES) systems can largely enhance the reliability and the dispatchability, allowing the production of electricity on demand [Ellingwood et al., 2020; Pelay et al., 2019; Zhang et al., 2016]. About half of the CSP plants currently in operation includes a TES system while this percentage rises up to more than $\mathbf{8 0 \%}$ for those planned and under construction [Pelay et al., 2017]. Progress in TES technologies thus plays a key role for the massive deployment of CSP plants regarding their cost-effectiveness and competitiveness [Li, 2016; Ortiz et al., 2019].

In today's most common CSP plants, the TES system is typically based on the sensible heat storage (mostly molten salts) using a two-tank assembly in which hot and cold heat transfer fluids (HTFs) are located in two separate tanks [Alva et al., 2018]. Thermocline TES technology on the other hand, consists in using only one tank instead of two. Both hot and cold HTFs are stored within the same tank but naturally separated from each other by the buoyancy force, with the presence of a temperature stratification zone called the thermocline. Compared to conventional two-tank TES systems, the single-tank thermocline storage is a more cost competitive option (about $35 \%$ cheaper) [Grirate et al., 2016; Motte et al., 2015], i.e., the reduced amount of high-priced HTF by about 70\% because of using cheap solid or industrial waste as energy storage material [Esence et al., 2017; Galione et al., 2015]. As a result, the interest for this technology is rapidly growing worldwide with a variety of new numerical and experimental developments being reported in the recent literature [Ahmed et al., 2019; Keilany et al., 2020; Pizzolato et al., 2017; Vigneshwaran et al., 2019].

The thermocline zone inside the storage tank is not motionless but evolves along with the dynamic operation of the TES system. During the charging (e.g., daytime), the hot HTF heated up in the solar field is introduced at the top of the tank and the thermocline zone moves downward. During the discharging (e.g., night), the cold HTF injected at the bottom of the tank pushes out the hot HTF (the stored heat) toward the power generation cycle and the thermocline zone moves upward. It is expected that the temperature stratification inside the storage tank should not be disturbed or degraded by the injected fluid flow during repeated charging-discharging cycles [Bruch et al., 2017; Zhao et al., 2017]. In real-world engineering however, the sudden expansion from the inlet port to the tank body may cause higher fluid velocity in the middle and lower velocity on the periphery of the tank. The flow non-uniformity, the local vortices and recirculation will cause the strong mixing of hot and cold HTFs and degrade the temperature stratification, resulting in the lower overall efficiency and the reduced storage capacity of the storage tank [Li, 2016]. Therefore, how to characterize and control the dynamic thermocline behaviors when injecting the HTF during charging/discharging is actually one of the major challenges for the design and operation of the thermocline TES tank in CSP plants. 
The vast majority of the earlier studies aim at achieving a uniform inlet velocity distribution or a horizontal flow front (velocity piston flow) leaving from the inlet port. For this reason, structured manifolds or fluid distributors are usually introduced for the inlet/outlet zones of the storage tank instead of simple injecting/outflowing ports. Afrin et al. [2013] proposed a pipe flow distributor with numerous sub-pipes to homogenize the fluid velocity distribution on the horizontal surface of a cylindrical TES tank. The effects of the number of sub-pipes, the locations/number of the holes on the sub-pipes were numerically studied. Kim et al. [2017] experimentally tested a multiport jet type inlet diffuser combined with a simple return outlet tube (without diffuser) in a single-medium TES for CSP application. They found that the diffuser was actually required for both inlet and outlet to alleviate the temperature deviation. In practice, the installation of perforated baffles at upper and bottom parts of the storage tank has been proposed by many researchers to approach the radially homogeneous velocity distribution over the cross-sections [Ahmed et al., 2019; Geissbühler et al., 2016; Yin et al., 2014; Zavattoni et al., 2017]. The conical or circular manifold with uniform orifices baffle was the most commonly used inlet/outlet structure in both numerical and experimental investigation to make sure that the fluid can be spread equally [De and Reuter, 2019; He et al., 2019; Nandi et al., 2018]. One exception is the work by Wang et al. [2015] which compared seven flow velocity profiles produced by different configurations of the inlet/outlet flow distributor. Their numerical results indicated that compared to uniform velocity profile, certain non-uniform flow profiles could lead to the reduced thermocline thickness and smaller entropy generation. This is actually in line with some observations reported in the literature [Kumar and Singh, 2019; Milman et al., 2012; Wei et al., 2015a] in that the optimal flow distribution is usually not uniform but obeys certain trend subjected to a defined optimization objective and constraints. However, controversy still exists on the relation between the optimal velocity profile and the expected thermocline evolution.

The full understanding of the complex transient transport phenomena (fluid flow, heat transfer, etc.) inside the single-medium thermocline storage tank is still lacking on the basis of above literature survey. In particular, the relation between the optimal velocity profile of HTFs produced by the inlet distributor and the minimum thermocline thickness is unclear. Furthermore, certain of the most widely used performance indicators like thermocline thickness or stratification number seem not to be totally adapted for characterizing real-world single-medium TES tanks. Moreover, investigations on effective solutions to maintain the temperature stratification during dynamic charging/discharging operations are needed.

The present study seeks to fill the research gap by appropriately structuring the inlet/outlet manifolds, using perforated baffles having optimized size distribution of orifices. Computational Fluid Dynamics (CFD) simulations were performed to characterize the transient fluid flow and heat transfer behaviors inside the storage tank. The main objectives and originalities of this paper are then threefold: (1) to reveal the fact that instead of uniform velocity profiles on the cross-sections, the flat thermal front (thermally piston flow) renders the highest level of temperature stratification in the storage tank; (2) to manage the HTF flow distribution by using optimized orifice baffles, so as to enhance the thermal performance of the thermocline storage tank; and (3) to propose and 
develop a heuristic algorithm coupled with a novel optimality criterion that can effectively determine the optimal size distribution of the orifices on the baffle.

It should be noted that the strategy for flow distribution management coupled with novel optimized baffled fluid distributor/collector has been proposed and proven to be really effective in our earlier studies [Luo et al., 2015; Wei et al., 2015b; Wei et al., 2016; Wei et al., 2017]. But in the current study, this method is for the first time applied to a more complicated situation (TES tank) to tackle the dynamic thermocline behavior optimization problem. The contributions of this paper are important because it will expand the limited literature and provide additional insights to issues involving the flow distribution optimization and thermocline evolution management in the storage tank. The results obtained may be used for the large deployment of the thermocline TES technology in future CSP plants.

The rest of the paper is organized as follows. The novel optimality criterion and the basic principles of the heuristic algorithm are described in detail in section 2. A 2D numerical benchmark is then introduced and optimization results are presented and compared in section 3 . The influences of various design and operational parameters are analyzed and discussed in section 4 . Finally in section 5, main findings and perspectives are summarized.

\section{Methodology for modeling and optimization}

This section presents the basic principles of the CFD-based heuristic algorithm for optimizing the thermal performance of the thermocline storage tank. The following assumptions and simplifications have been made for this study.

- Incompressible Newtonian fluid;

- 2D flow domain;

- No solid filler in the storage tank;

- The storage tank is well-insulated, i.e., negligible heat loss to the environment;

- Constant injecting HTF temperatures for charging $\left(T_{H}\right)$ and for discharging $\left(T_{L}\right)$, respectively;

- Homogeneous temperature profile in the storage tank at the initial-state $\left(t_{0}\right)$.

\subsection{Parameter definition}

Figure 1 shows the schematic view of the thermocline storage tank used as a representative model for the current study. It is a simplified 2D domain of $H$ in height and $L$ in length, having single inlet port and outlet port in the center. Two perforated baffles are installed at the upper and bottom parts of the storage tank, dividing the whole domain into three consecutive zones: the upper manifold from the upper port to the upper baffle; the middle flow zone and the bottom manifold from the bottom baffle to the bottom port. The height of middle flow zone is $h$, with three cuttingsections (P1, P2, P3) marked for monitoring. The void volume for the fluid is noted as $S_{t o t}$, representing the surface area of the fluid domain from the upper port to bottom port, except for the solid part of baffles. 
The length of the perforated baffles equals to the length of the storage tank and their thickness is $e$. The upper baffle is divided into $N$ control units of identical length $\left(L_{\text {unit }}\right)$, indexed by $i$ from 1 to $N$ from the left side to the right side. For each control unit, there is one orifice of width $d_{i}$ arranged in the middle, as shown in Fig. 1 . Note that $\alpha_{i}$ is defined as the local porosity of $i$ th control unit and $\Phi$ the global porosity of the baffle. Assuming that every orifice can't exceed the boundary of its control unit $\left(d_{i}<L_{\text {unit }}\right)$, the following geometric relations can be written:

$$
\begin{aligned}
& L_{\text {unit }}=\frac{L}{N} \\
& \alpha_{i}=\frac{d_{i}}{L_{\text {unit }}}<1 \\
& \Phi=\frac{\sum d_{i}}{L}=\frac{\sum \alpha_{i}}{N}
\end{aligned}
$$

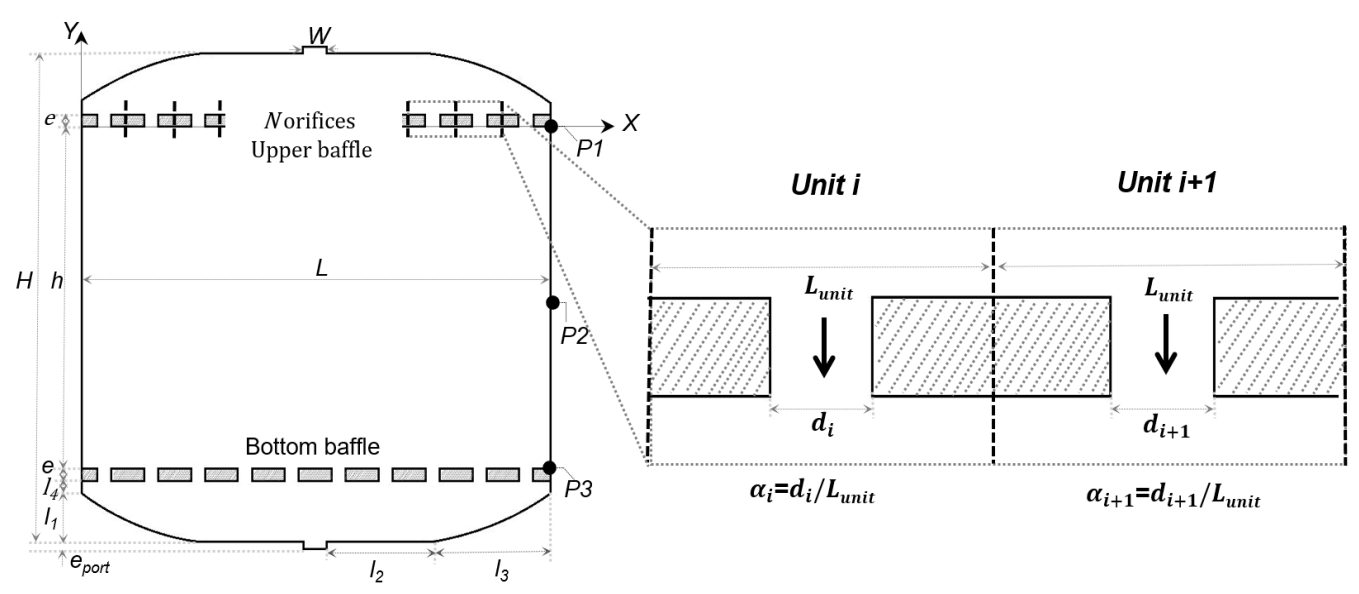

Figure I. Schematic view of a 2D thermocline storage tank equipped with upper and bottom orifice baffles

For the charging process, the storage tank is supposed to be fully filled with the cold HTF at homogeneous temperature $T_{L}$ at the initial state $t_{0}$. Once the charging begins, the hot HTF at constant temperature $\left(T_{H}\right)$ is injected into the upper port at constant flow-rate $\dot{m}_{H}$. It flows from top to bottom, passing consecutively through the upper manifold zone, the middle flow zone and the bottom manifold zone. At the same time, the cold HTF is forced out from the bottom port so that the thermal energy is stored in the tank. The discharging process is actually the reverse operation in which the storage tank is initially filled with hot HTF at constant and uniform temperature $T_{H}$. The cold HTF $\left(T_{L} ; \dot{m}_{L}\right)$ is then injected into the bottom port and flows from the bottom to the top to release the stored thermal energy.

We define $T_{X}$ as a temperature value within the range of $T_{L}$ to $T_{H}$, calculated by Eq. (4).

$$
T_{x}=T_{L}+x \% \times\left(T_{H}-T_{L}\right)
$$

The threshold coefficient at $x=20$ is used in this study to define the temperature borders or fronts $\left[T_{20}, T_{80}\right]$. These two temperature fronts divide the storage tank into three regions: the hot zone usually at the top part of the tank, the cold zone at the bottom, and the thermocline region enclosed by the hot and cold fronts. The time and spatial evolution of the hot front $T_{80}$ and the cold 
front $T_{20}$ during the charging or discharging operations determines then the shape and the surface area of the thermocline zone, as indicated in Fig. 3. We define $S(t)$ as the surface area having temperatures between $T_{20}$ and $T_{80}$ at time $t$. Then the dimensionless surface area of the thermocline zone $S^{*}(t)$ can be obtained by dividing $S(t)$ by the total void fluid domain $\left(S_{t o t}\right)$, shown in Eq.(5):

$$
S^{*}(t)=\frac{S(t)}{S_{t o t}}
$$

Compared to dual-media TES tanks with sensible/latent fillers, the thermocline shape of singlemedium TES tank is normally more complex because of the non-uniform velocity profiles and the strong time and spatial evolution of thermal fronts induced by the momentum-dominated entering jet. For this reason, the thermocline surface area, rather than the thermocline thickness, is used here as the indicator to characterize the thermocline zone.

\subsection{Performance indicators}

Some global performance indicators commonly used in the literature [Zanganeh et al., 2015] are introduced to indicate the thermal performance of the storage tank, including the charging/discharging efficiency $(\eta)$, the overall efficiency $\left(\eta_{\text {overall }}\right)$ and the capacity ratio $(\sigma)$. Their definitions are shown in Eqs. (6-9).

$$
\eta_{c h}=\frac{E_{\text {in }}-E_{\text {out }}}{E_{\text {in }}}=\frac{\int_{t_{0}}^{t_{f}}\left(\dot{m}_{\text {in }} C p_{\text {in }} T_{\text {in }}-\dot{m}_{\text {out }} C p_{\text {out }} T_{\text {out }}\right) d t}{\int_{t_{0}}^{t_{f}} \dot{m}_{\text {in }} C p_{\text {in }} T_{\text {in }} d t}
$$

$$
\eta_{\text {dis }}=\frac{E_{\text {out }}-E_{\text {in }}}{E_{\text {stored }}}=\frac{\int_{t_{0}}^{t_{f}}\left(\dot{m}_{\text {out }} C p_{\text {out }} T_{\text {out }}-\dot{m}_{\text {in }} C p_{\text {in }} T_{\text {in }}\right) d t}{E_{\text {stored }}}
$$

$$
\eta_{\text {overall }}=\eta_{c h} \eta_{\text {dis }}
$$

Where $T_{\text {in }}$ and $T_{\text {out }}$ are the inlet and outlet temperature of the HTF, respectively. $C p$ is the temperature-dependent specific heat of the HTF and $\dot{m}$ is the mass flow-rate. $t_{f}$ is the end time for fully charging/discharging process $\left(T_{\text {out }}=T_{99}\right.$ for charging and $T_{\text {out }}=T_{01}$ for discharging).

$$
\text { Capacity ratio } \sigma=\frac{E_{\text {stored }}}{E_{\text {stored }}^{\text {max }}}=\frac{E_{\text {in }}-E_{\text {out }}}{S_{\text {tot }}\left(C p_{H} T_{H} \rho_{H}-C p_{L} T_{L} \rho_{L}\right)}
$$

The capacity ratio $(\sigma)$ indicates the ratio of real stored thermal energy to the maximum energy storage capacity of the tank. As a result, $\sigma$ equals to 1 for fully charging/discharging operations but is smaller than 1 for partial charging/discharging. In this study, the cut-off outlet temperature is set as $T_{20}$ for the charging process.

For a CSP plant with integrated TES system, the outlet HTF temperature from its attached TES system seems to be one of the most important parameters that should be closely monitored and controlled during dynamic operations. During charging, the outlet HTF from the TES system toward the solar field should not be overheated so as to avoid the inconvenient control operations 
such as the solar field defocusing or the HTF mass flow variation [Fasquelle et al., 2018a; Sanz et al., 2019]. During discharging, the subcooling of the outflowing HTF from the storage tank to the power generation cycle should also be prevented [Modi and Pérez-Segarra, 2014]. Particularly for the thermocline storage tank, an appropriate cut-off temperature has to be defined to prevent the overheating/subcooling on one hand, and to guarantee a high storage capacity on the other hand. Several methods about the selection of the cut-off temperature are proposed [Modi and PérezSegarra, 2014] and the threshold values $\left[T_{20}, T_{80}\right]$ are commonly used [Fasquelle et al., 2018b]. In real-world engineering however, a high-steep slope for the $T_{\text {out }}$ curve is strongly expected to have a more flexible range of the cut-off temperature as well as a higher capacity ratio.

In order to unfold the information on the slop of the $T_{\text {out }}$ curve that cannot be indicated by the efficiencies or the capacity ratio, a new performance indicator, namely the tail factor $(\varepsilon)$, is proposed and introduced here. It is defined as the slope of the dimensionless HTF outlet temperature $\left(T_{\text {out }}^{*}\right)$ and the dimensionless time, as shown and explained in Eqs. $(10 ; 11)$ and Fig. 2.
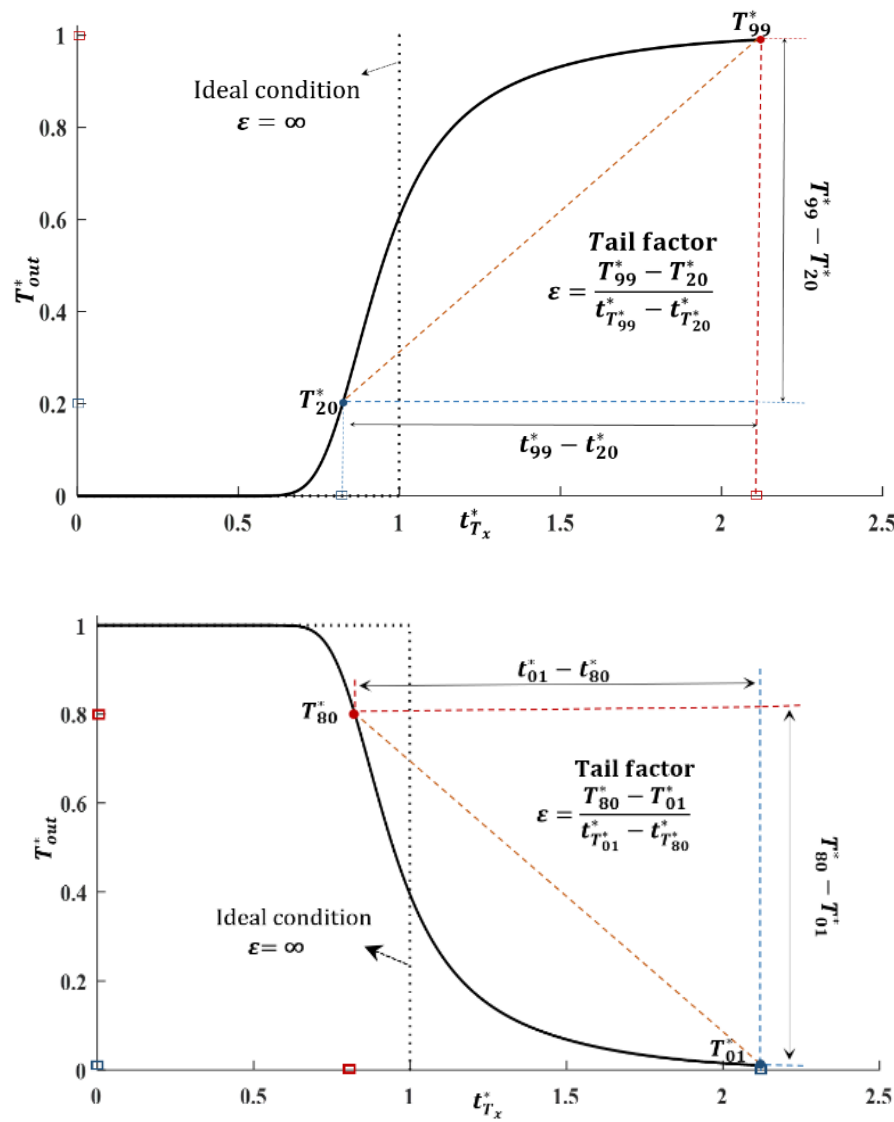

(b)

Figure 2. Definition of tail factor $\varepsilon$ for the charging (a) and the discharging (b) in a thermocline storage tank

$$
\varepsilon_{c h}=\frac{T_{99}^{*}-T_{20}^{*}}{t_{T_{99}^{*}}^{*}-t_{T_{20}^{*}}^{*}}
$$

$$
\varepsilon_{d i s}=\frac{T_{80}^{*}-T_{01}^{*}}{t_{T_{01}^{*}}^{*}-t_{T_{80}^{*}}^{*}}
$$

where the dimensionless temperature $T_{x}^{*}$ is calculated by Eq. (12): 


$$
T_{x}^{*}=\frac{T_{x}}{\left(T_{H}-T_{L}\right)}
$$

$t_{T_{x}}^{*}$ is the dimensionless time calculated by Eq. (13), where $t_{T_{x}}$ indicates the moment when the HTF outlet temperature reaches $T_{X}$.

$$
t_{T_{x}}^{*}=\frac{t_{T_{x}}}{t_{\text {ideal }}}
$$

The denominator $t_{\text {ideal }}$ in Eq. (13) is the overall passage time for an ideal storage tank with perfect temperature stratification (thermally piston flow without heat exchange), calculated by Eq. (14).

$$
t_{\text {ideal }}=\frac{s_{\text {tot }}}{v_{\text {in }} W_{\text {in }}}
$$

where $v_{\text {in }}$ is the velocity of the inlet HTF.

The higher value of $\varepsilon$ means that the shape of $T_{\text {out }}^{*}$ curve as a function of time is closer to a step line, implying that the thermocline storage tank is operated close to the ideal condition. The definition of tail factor excludes the influences of the used HTF type and their thermo-physical properties (e.g., $C p, \rho$ ), thereby more direct and more convenient to calculate. By comparing the $\varepsilon$ value of real charging/discharging process with that of ideal case $(\varepsilon=\infty)$, the level of temperature stratification can then be quantified.

One may also notice that to calculate these performance indicators, the fully charging or discharging process should be simulated. The employment of an intermediate parameter having certain connections to these global indicators may be beneficial to ease the calculation burden.

\subsection{Heuristic optimality criterion}

Most of the studies in the literature aim at achieving uniform velocity profile on the horizontal surface of the thermocline storage tank. Here we propose that a thermally piston flow with flat thermal front could be more beneficial. However, this is difficult to achieve even at the presence of the perforated baffle, as explained in Fig. 3 for a typical charging process. 


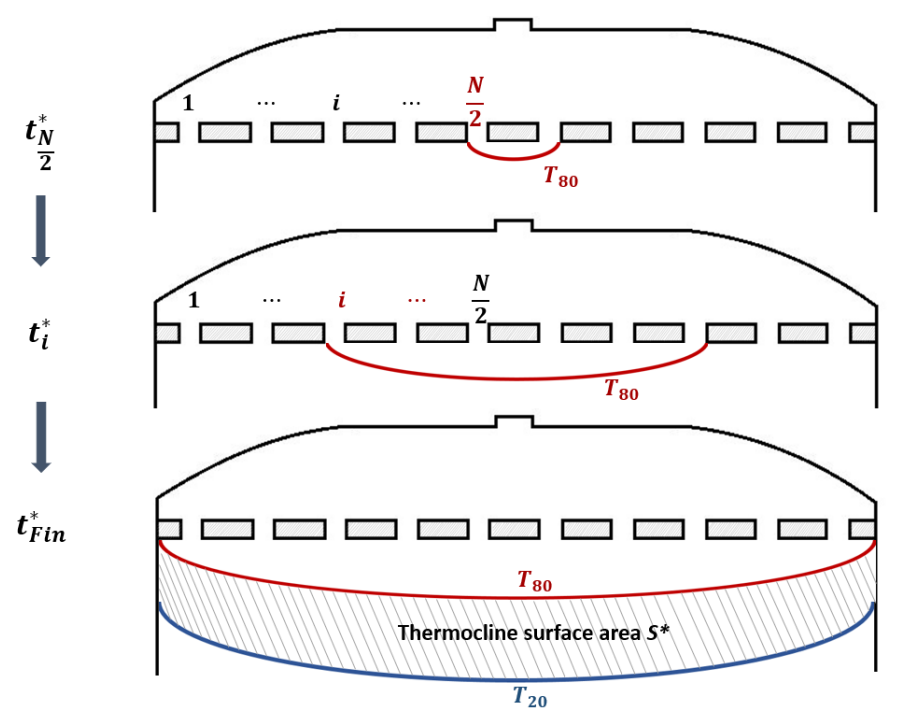

Figure 3. Schematic view on the evolution of the thermal front during the charging process

At $t_{0}$ time state, the storage tank is full of the cold HTF at homogeneous temperature $T_{L}$. Once the charging begins, the hot HTF at $T_{H}$ will be injected into the upper port, getting in contact the cold HTF in the upper manifold. A temperature transition zone will then occur due to the heat transfer between the hot and cold HTFs. The hot front $\left(T_{80}\right)$ will firstly pass through the middle orifices $(i=N / 2 ; N / 2+1)$ facing to the upper port and then extend towards the orifices situated on the side (e.g., $i=1 ; N)$. Generally for orifice $i$, its mean fluid temperature passing through $\left(T_{i}(t)\right)$ increases over time from $T_{L}$ to $T_{20}$ then to $T_{80}$, and finally reaches $T_{H}$. We define the passage time $t_{i}$ as the time when the hot front $\left(T_{80}\right)$ passes through the orifice $i$ :

$$
T_{i}\left(t_{i}\right)=T_{80}
$$

Evidently for different orifices, their passage times are not identical. Middle orifices have shorter passages time compared to those on the side due to the shorter distance to the upper port and relatively higher velocity magnitude. The dimensionless mean passage time for all the orifices can be calculated by Eq. (16).

$$
\overline{t^{*}}=\frac{\sum_{i=1}^{N} t_{i}^{*}}{N}=\frac{\sum_{i=1}^{N} t_{i}}{N t_{\text {ideal }}}
$$

We define $t_{F i n}^{*}$ as the moment when the hot front $T_{80}$ totally passes through the upper manifold, the corresponding dimensionless thermocline surface area being $S^{*}\left(t_{\text {Fin }}^{*}\right)$, as shown in Fig. 3. $S^{*}\left(t_{\text {Fin }}^{*}\right)$ is actually an intermediate value that will still evolve along with the subsequent charging process. The relation between this intermediate indicator and some global performance indicators will be discussed later.

The basic idea of the optimization method is to adjust the size distribution of perforated orifices on the baffle so that the thermal front $T_{80}$ could pass through every orifice at almost the same time. This thermally piston flow can consequently minimize the $S^{*}$ value at $t_{\text {Fin }}^{*}$ moment so that the temperature stratification in the storage tank can be maintained. Here we propose a heuristic 
optimality criterion, suggesting that the thermally piston flow could be realized when the passage times $\left(t_{i}^{*}\right)$ for orifices are identical (Eq. 17):

$$
t_{i}^{*}=\overline{t^{*}}(i=1,2 \ldots N)
$$

With this optimality criterion in hand, an original CFD-based optimization algorithm has been developed.

\subsection{Basic principle of the optimization algorithm}

The optimization algorithm is developed to determine the optimal size distribution of orifices on the perforated baffle so as to homogenize the passages times of the thermal front. As explained in Fig. 4 , the local porosity of $i$ th orifice $\left(\alpha_{i}\right)$ is varied simultaneously by comparing its passage time $\left(t_{i}^{*}\right)$ and the mean value of all passage times $\left(\overline{t^{*}}\right)$. Specifically for $j$ optimization step, if $t_{i, j}^{*}$ is greater than $\overline{t_{j}^{*}}$, the size of orifice $i$ will be enlarged to get a relatively smaller passage time $t_{i, j+1}^{*}$ at step $j+1$. Otherwise, if $t_{i, j}^{*}$ is lower than $\overline{t_{j}^{*}}$, the value of of $\alpha_{i, j+1}$ will be reduced to lengthen the passage time $t_{i, j+1}^{*}$ of the thermal front. This variation rule from $j$ to $j+1$ step for $i$ th orifice is written in Eq. (18).

$$
\Delta \alpha_{i, j}=\alpha_{i, j+1}-\alpha_{i, j}=\gamma\left(t_{i, j}^{*}-\overline{t_{j}^{*}}\right)
$$

Where $\gamma$ is a relaxation factor chosen to ensure a fast and stable convergence. Following this variation rule, one may easily verify that although the local porosity $\alpha_{i}$ varies from one iteration to the next, the global porosity of the baffle $\Phi$ is kept constant (Eq. 19).

$$
\sum_{i=1}^{N} \Delta \alpha_{i, j}=\sum_{i=1}^{N}\left(\alpha_{i, j+1}-\alpha_{i, j}\right)=\sum_{i=1}^{N} \alpha_{i, j+1}-\sum_{i=1}^{N} \alpha_{i, j}=\Phi_{j+1}-\Phi_{j}=0
$$

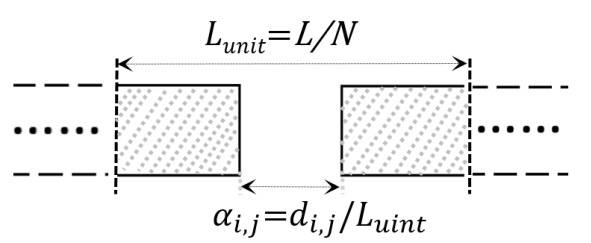

Step $j$

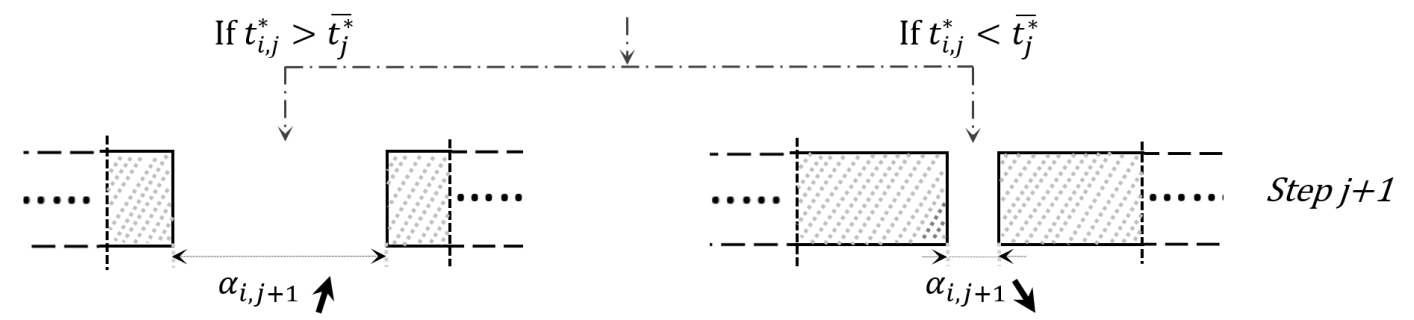

Figure 4. Basic principle of the optimization algorithm for enlarging or reducing the size of an orifice

The degree of closeness between the optimized results and the optimality criterion is quantified by the standard deviation of the dimensionless passages times $\left(\mathrm{STD}_{t_{i}^{*}}\right)$ defined as follows: 
2

\subsection{Numerical implementation}

An automatic program is developed to realize the iterative procedure of the heuristic algorithm. Its major steps are schematized in the flow chart of Fig. 5 and are described in detail below.

(1) Input the geometry of the storage tank (height, length, cone angle, etc.) and the physical properties of the HTF.

(2) Definition of the parameters relative to the upper \& bottom perforated baffles, such as the location and thickness, the orifice number $N$ and the global porosity $\Phi$, the size distribution of orifices.

(3) Mesh generation of the whole simulation domain.

(4) Set of boundary and initial conditions (initial temperature state, operating temperatures, inlet flow-rate, etc.).

(5) CFD simulation of the transient flow and temperature profiles in the storage tank from $t_{0}$ to $t_{\text {Fin }}^{*}$

(6) Calculation of the dimensionless thermocline surface area $S^{*}\left(t_{\text {Fin }}^{*}\right)(\mathrm{Eq} .(5))$; calculation of the passage time $t_{i}^{*}$ for each orifice. Modification of the baffle configuration by comparing $t_{i}^{*}$ and $\overline{t^{*}}$ according to the variation rule in $\mathrm{Eq} .(18)$.

(7) Regeneration of the mesh for the updated simulation domain; recalculation of the transient flow and temperature profiles in the storage tank from to to $t_{\text {Fin }}^{*}$.

(8) Check the stable tolerance of the algorithm. If the tolerance is satisfied, then the iteration procedure is terminated. If not so, the procedure goes back to step 2 for recurrence. The result is considered to be stable when the variation of $\Delta S^{*}\left(t_{F i n}^{*}\right)$ is smaller than $1 \%$ from $j$ to $j+1$ iteration $\operatorname{step}(\mathrm{Eq} .21)$.

$$
\Delta S^{*}\left(t_{F i n}^{*}\right)=\frac{S_{j+1}^{*}-S_{j}^{*}}{\frac{1}{2}\left(S_{j+1}^{*}+S_{j}^{*}\right)}<0.01
$$

(9) Continue the simulation of full charging (or discharging) process until the $T_{\text {out }}^{*}$ reaches $T_{99}^{*}\left(\right.$ or $\left.T_{01}^{*}\right)$. Export the final baffle configurations and the values of the global performance indicators $(\eta, \sigma, \varepsilon)$. 


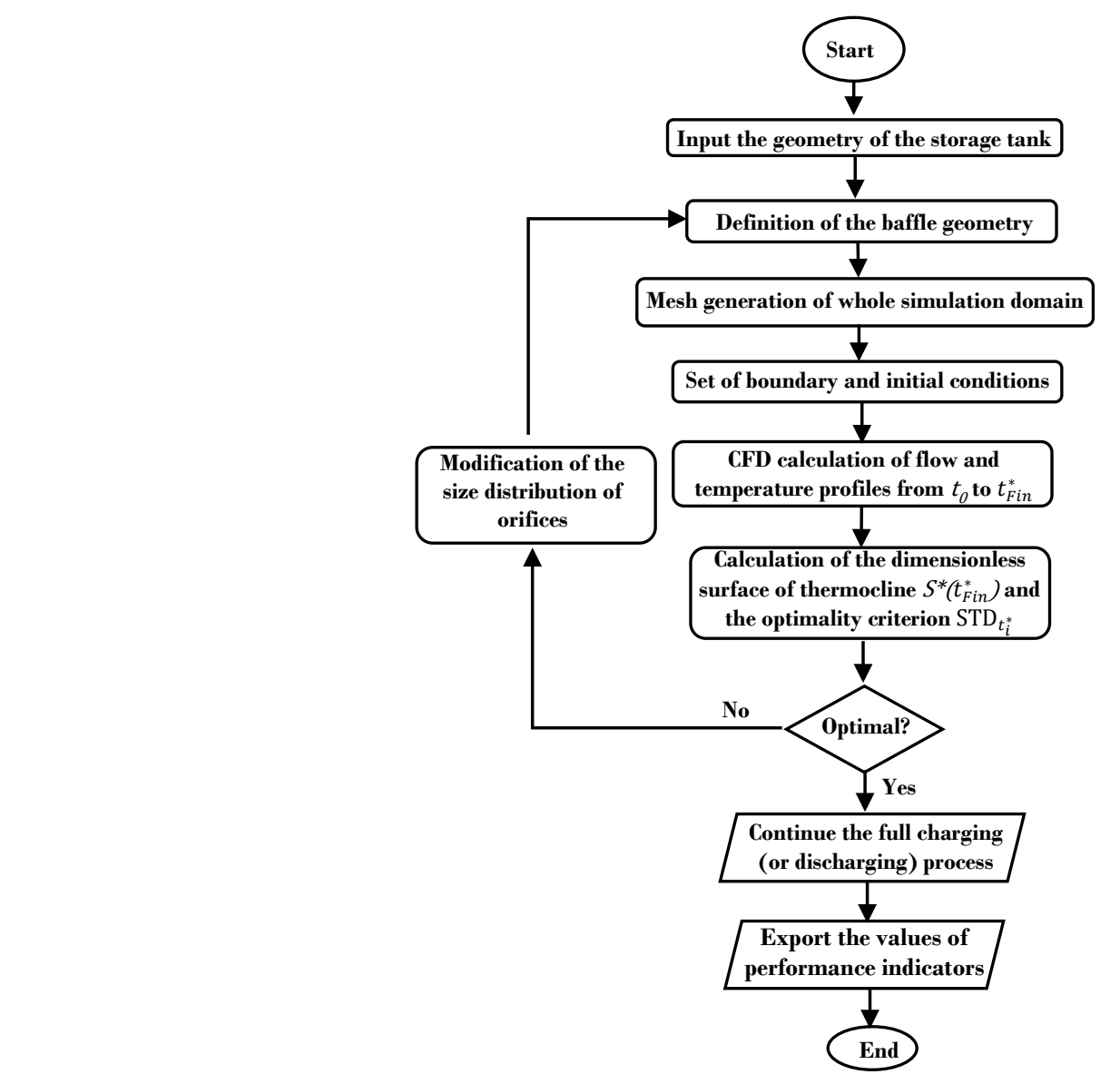

Figure 5. Flow chart of the optimization algorithm

\section{Simulation and results}

In this section, the simulation parameters and results for a storage tank are presented to showcase the feasibility and the effectiveness of the proposed optimization algorithm.

\subsection{Geometries and simulation parameters}

A 2D simulation domain as shown in Fig. 1 has been created as the benchmark case to represent the storage tank. Its main dimensions are listed in Table 1. An upper and a bottom baffle were installed in the storage tank to regulate the thermal front behaviors. Their dimensions are also listed in Table 1 . There are 10 orifices on each baffle $(N=10)$, the global porosity $(\Phi)$ being 0.3 . The void volume $S_{t o t}$ equals to $0.03713 \mathrm{~m}^{2}$. Identical size of orifices $\left(\alpha_{i, 0}=\Phi, i=1,2, \ldots N\right)$ was set for both baffles at the starting point $(j=0)$. Recall that for the charging process, the size distribution of orifices on the upper baffle will evolve according to the optimization algorithm while that on the bottom baffle remains unchanged, and vice versa for the discharging process. A reference case with empty upper baffle for the charging is also included for comparison, noted hereafter as step $j=-1$. 
The influence of the upper \& bottom baffle combinations on the thermocline behaviors will be discussed later.

Table I. Main geometric dimensions for the benchmark storage tank (unit: $\mathbf{m m}$ )

\begin{tabular}{llllllllllll}
\hline Parameter & $H$ & $h$ & $L$ & $W$ & $N(-)$ & $e$ & $e_{\text {port }}$ & $I_{1}$ & $I_{2}$ & $I_{3}$ & $I_{4}$ \\
\hline Value & 200 & 140 & 200 & 10 & 10 & 5 & 3 & 20 & 35 & 60 & 5 \\
\hline
\end{tabular}

The working HTF used is the solar salt. Its thermophysical properties were considered as temperature-dependent, except for the density, which was assumed to be constant at $1818.5 \mathrm{~kg} \mathrm{~m}^{-3}$ (Table 2).

Table.2. Thermo-physical properties of the HTF [Hoffmann et al., 20 I6]

\begin{tabular}{llll}
\hline Material & Property & Unit & Fitting correlation $T\left({ }^{\circ} \mathrm{C}\right)$ \\
\hline Solar salt & Density $\rho$ & $\mathrm{kg} \mathrm{m}^{-3}$ & $1818.5(700 \mathrm{~K})$ \\
$(600 \mathrm{~K}<T<800 \mathrm{~K})$ & Specific heat $C p$ & $\mathrm{~J} \mathrm{~kg}^{-1} \mathrm{~K}^{-1}$ & $1443+0.172 T$ \\
& Thermal conductivity $\lambda$ & $\mathrm{W} \mathrm{m}^{-1} \mathrm{~K}^{-1}$ & $0.443+0.00019 T$ \\
& Dynamic viscosity $\mu$ & $\mathrm{kg} \mathrm{m}^{-1} \mathrm{~S}^{-1}$ & $\left(22.174-0.12 T+2.281 \times 10^{-4} T^{2}\right.$ \\
& & & $\left.-1.474 \times 10^{-7} T^{3}\right) / 1000$ \\
\hline
\end{tabular}

Constant velocity normal to the inlet port surface was set as the inlet boundary condition. The outlet boundary condition was set as pressure-outlet with zero static pressure. All the walls for the storage tank were defined as non-slip and adiabatic. The operational pressure was fixed at 101325 Pa. For the charging process, the fluid zone was initialized as $T_{L}=600 \mathrm{~K}$ (fully occupied by the cold HTF). Hot HTF $\left(T_{H}=800 \mathrm{~K}\right)$ was injected into the upper port at $0.00288 \mathrm{~m} \cdot \mathrm{s}^{-1}$. The Reynolds number in the tank equals to 50, based on the mean temperature of hot and cold HTF (700 K). Vice versa for the discharging process, the fluid zone was initialized as $T_{H}=800 \mathrm{~K}$ and cold $\mathrm{HTF}\left(T_{L}=600\right.$ $\mathrm{K})$ was injected into the bottom port.

Fluid flow and temperature profiles in the storage tank were calculated by using Ansys FLUENT code (version 17.2). Finite-volume method with collocated grid at vertex was applied for numerical discretization. Second-order upwind differential scheme was applied for momentum and standard method for pressure. SIMPLE method was used for the pressure-velocity coupling in order to correct the pressure field oscillations [Rodrigues \& Lemos, 2020]. Simulations were performed under transient state with fixed time step of $0.2 \mathrm{~s}$. The solution was considered to be converged when (i) normalized residuals were smaller than $10^{-5}$ for mass and momentum equations and $10^{-7}$ for energy equation, and (ii) the inlet static pressure become constant (less than $0.5 \%$ variation).

For each iteration step of the optimization algorithm, MATLAB R2016b was used for data postprocessing of the computed flow and temperature profiles from FLUENT, to calculate the size variation of each orifice according to Eq. (18) and to pass the renewed geometric coordinates to Ansys Workbench for a new CFD simulation. 
The structured model mesh was refined to raise the calculation accuracy and to speed up the convergence. A grid independence test was performed with the increased number of total elements from $30 \mathrm{k}$ to $400 \mathrm{k}$. It can be observed in Fig. 6 that the difference in $\Delta S^{*}\left(t_{F i n}^{*}\right)$ is less than $1 \%$ when the number of elements is higher than $200 \mathrm{k}$. Therefore, the mesh with $200 \mathrm{k}$ elements has been used in the following study for a compromise between accuracy and computational time.

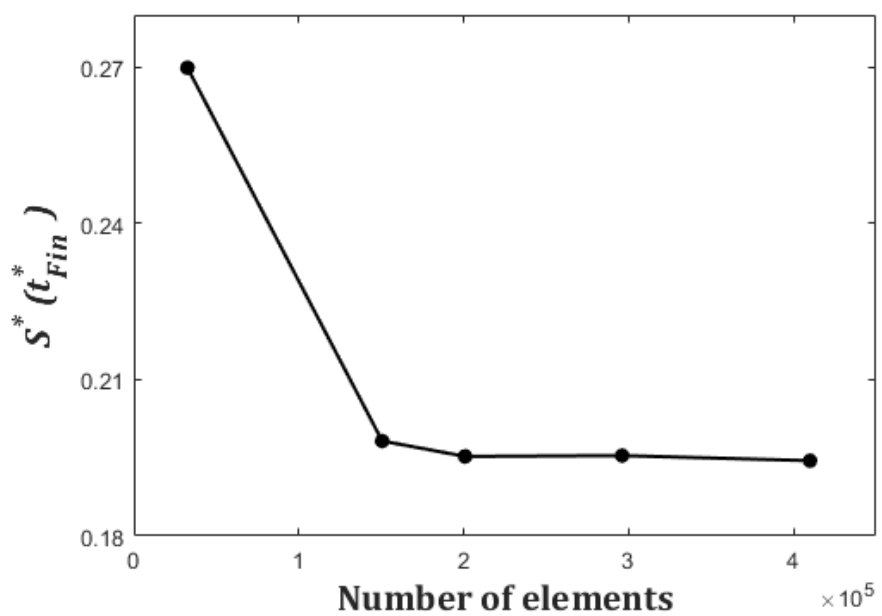

Figure 6. Grid independence test based on the dimensionless thermocline surface area $S^{*}\left(t_{\text {Fin }}^{*}\right)$

\subsection{Optimization of the upper baffle for charging process}

Figure 7 shows the evolution of the dimensionless thermocline surface area $\left(S^{*}\right)$ and the standard deviation of passages times $\left(\mathrm{STD}_{t_{i}^{*}}\right)$ as a function of the optimization step. It can be seen that the values of $\mathrm{STD}_{t_{i}^{*}}$ are 0.598 for the no upper baffle case $(j=-1)$ and 0.224 for the uniform orifice baffle case $(j=0)$, indicating non-identical passage times. When the optimization algorithm proceeds from one step to the next, both the values of $\operatorname{STD}_{t_{i}^{*}}$ and $S^{*}$ decrease rapidly, indicating the coherence of the proposed optimality criterion. Finally convergence $\left(\Delta S^{*}\left(t_{F i n}^{*}\right)<0.01\right)$ can be reached after 6 optimization steps, showing that the CFD-based optimization algorithm is effective and fast approaches the optimum.

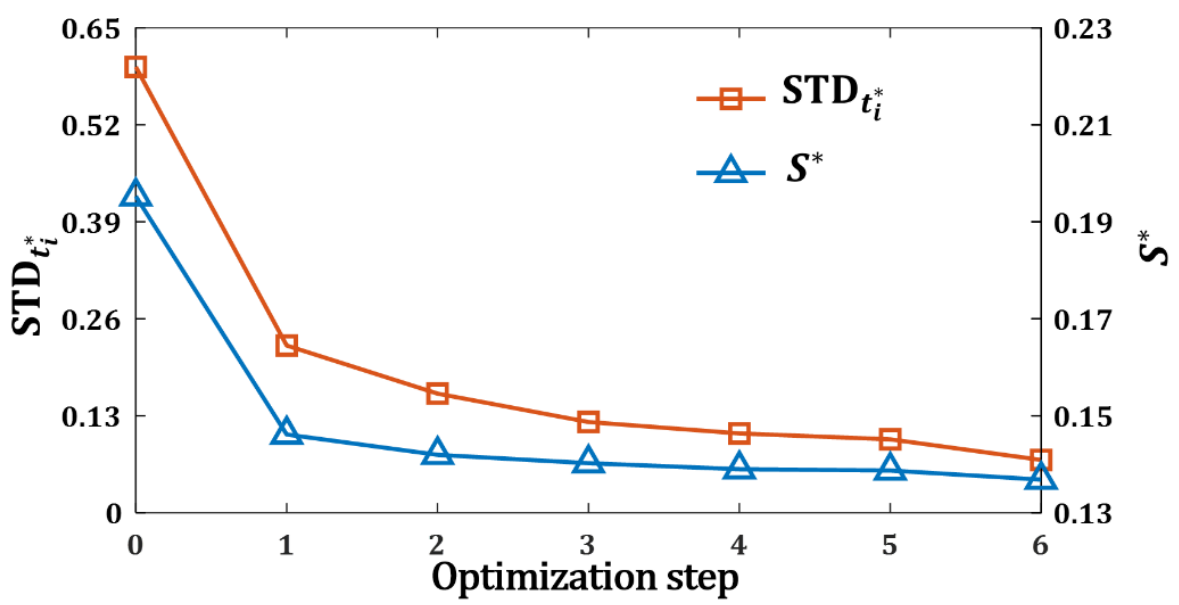
optimization step 
Figure 8 gives a comparison on the evolution of temperature profile in the storage tank from $t_{0}$ to $t_{\text {Fin }}^{*}$ for 3 cases (without upper baffle; uniform orifice upper baffle; optimized upper baffle). When no baffle is installed in the upper manifold $(j=-1)$, hot HTF injected in the center upper port causes higher fluid velocity in the middle and lower velocity on the periphery of the storage tank (also shown by case 1 in Fig. 10). The thermal front expands radially and the temperature stratification is totally disturbed due to the strong mixing of hot and cold HTFs. At $t_{\text {Fin }}^{*}$ moment, the temperature of HTF at the bottom port $\left(T_{o u t}^{*}\right)$ has already reached $T_{80}^{*}$. The temperature transitional zone (the thermocline) propagates to the whole height of the storage tank, implying low thermal performance and reduced storage capacity.

The insertion of a uniform orifice upper baffle $(j=0)$ serves as an additional flow resistance to block the downward jet flow of hot HTF, leading to the alleviated velocity peak in the middle of the tank (case 2 in Fig. 10). The thermocline zone propagates slower in the vertical (Y) direction but instead extends toward the lateral $(X)$ direction in the upper manifold. Nevertheless, the thermal front still shows a parabolic shape which is far from the expected thermally piston flow. At $t_{\text {Fin }}^{*}$ moment when the hot front $T_{80}^{*}$ totally passes cross the upper manifold, the cold front $T_{20}^{*}$ almost touches the bottom baffle.

By running the optimization algorithm, the sizes of middle orifices become smaller while those near the walls are enlarged. Consequently, the injected hot HTF is further guided toward the lateral walls in the upper manifold (case 3 in Fig. 10), so does the thermocline zone. The hot HTF tends to occupy the whole upper manifold before crossing through the optimized upper baffle. Almost flat hot and cold fronts can be observed at $1 / 2 t_{\text {Fin }}^{*}$ on Fig. 8, indicating that quasi-thermally piston flow has been achieved. After that, the thermocline zone still evolves and exhibits a double-hump shape at the $t_{\text {Fin }}^{*}$ moment, due to the relatively higher velocities of the hot HTF near the side walls during the whole charging process. This characteristic of negative parabolic shaped velocity profile is also clearly shown at the case 3 in Fig. 10 . Nevertheless, the surface area of the thermocline zone is the smallest after optimization, indicated by the smallest $S^{*}$ value $(0.14)$ compared to that without baffle case $\left(S^{*}=0.33\right)$ or uniform orifice baffle case $\left(S^{*}=0.20\right)$. 


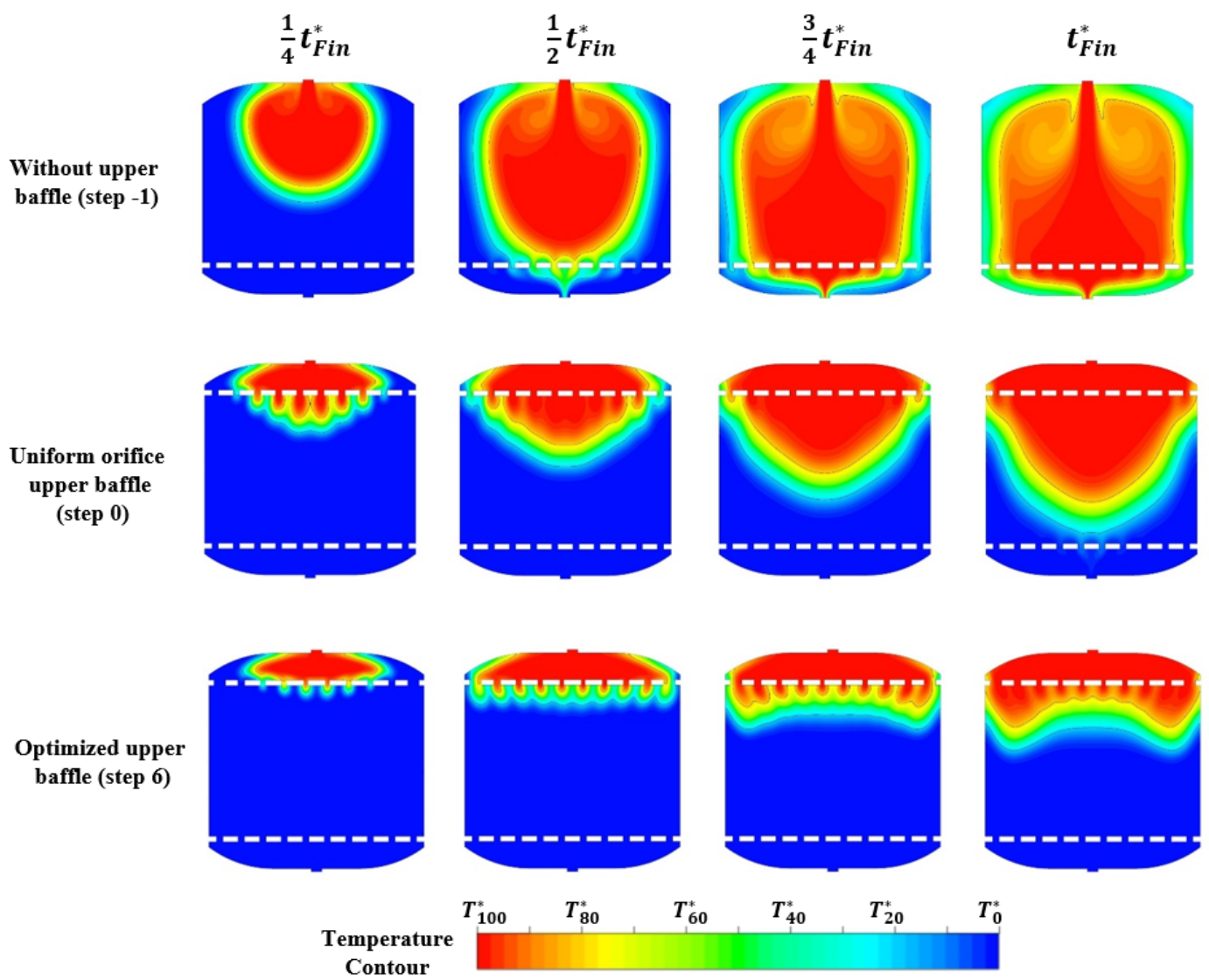

Figure 8. Comparison on the evolution of the temperature profiles in the storage tank from to to $t_{\text {Fin }}^{*}$ during the charging process

Figure 9 shows the $T_{\text {out }}^{*}$ curves as a function of the dimensionless time $t^{*}$ for different cases. It can be observed that the curve for the non-upper baffle case has a long tail ( $\varepsilon=0.137)$, indicating that it takes very long time for $T_{o u t}^{*}$ to reach $T_{99}^{*}$. On the contrary, the slope of curve for the optimized upper baffle case is steeper $(\varepsilon=0.607)$, implying smaller mixing effect of hot and cold HTFs in the storage tank. Also indicated on Fig. 9 are values of some intermediate or global indicators introduced to evaluate the performance of the thermocline storage tank. Note that in addition to the three tested cases, the values for the ideal condition are also listed for comparison. Among the three tested cases, the optimized upper baffle case always presents the best values, showing the validity of the proposed optimality criterion and the effectiveness of the developed optimization algorithm.

Another remark is that the intermediate parameter is in close connection to the global performance indicators: minimizing the $S^{*}\left(t_{F i n}^{*}\right)$ leads to maximize the values of tail factor $(\varepsilon)$, fully charging efficiency $(\eta)$ and the capacity ratio $(\sigma)$. Instead of simulating the full charging (discharging) process, each iteration can be stopped at $t_{\text {Fin }}^{*}$ time. The whole calculation time can then be reduced by a factor of 6 at least, without influencing the optimization results. 


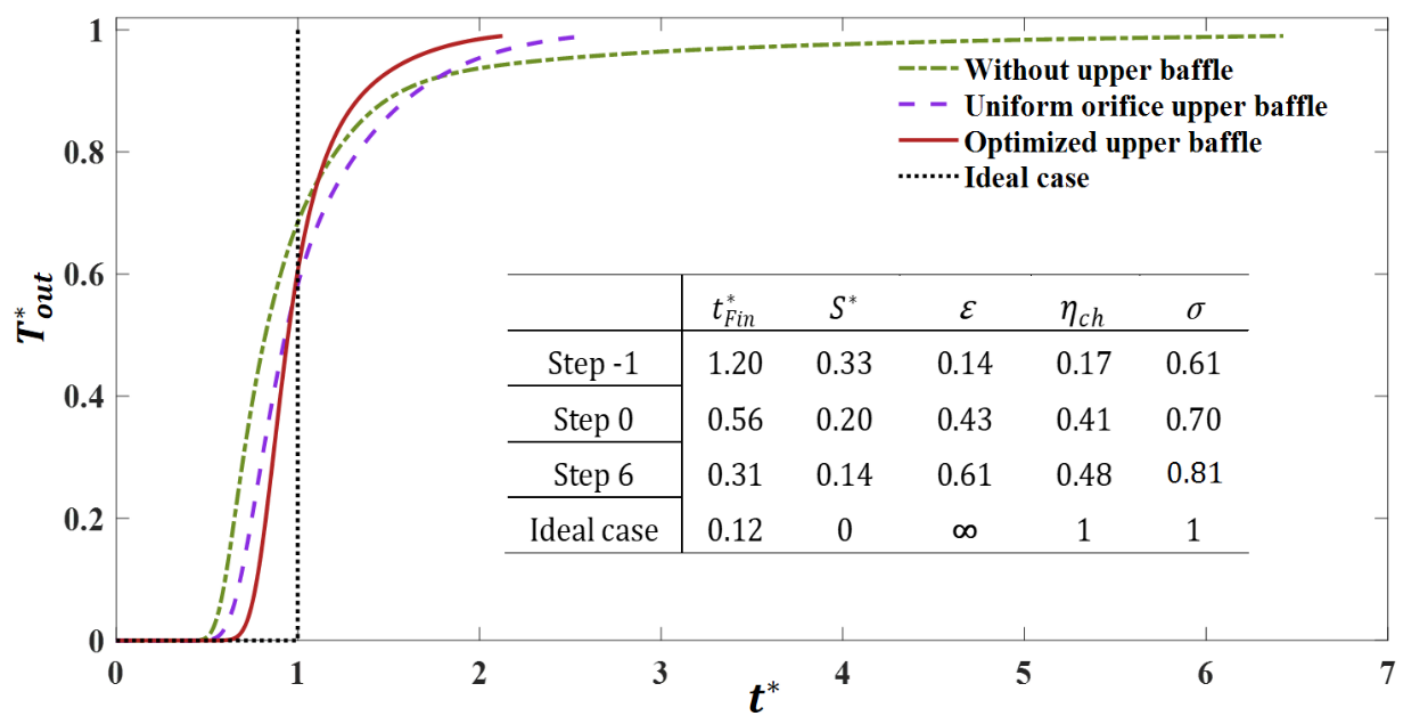

Figure 9. Comparison on different performance indicators for the tested cases

\subsection{Combination of upper \& bottom baffles for one cyclic operation (charging \& discharging processes)}

Note that the upper baffle has been optimized for the charging process when uniform orifice baffle is always used for the bottom manifold. However, the bottom baffle is also a matter of concern regarding the cyclic operation when the discharging process is included in particular. To complete the study, the bottom baffle is also optimized by running the algorithm during a fully discharging process when the optimized upper baffle is installed, as shown by Case 4 in Fig. 10. One may observe that the optimal orifice size distributions of bottom baffle is slightly differed from that of the upper baffle, mainly due to the impact of the gravity effect. However the global trend is the same: larger orifices close to the lateral walls whereas smaller orifices in the middle facing the upper/bottom ports.

The evolution of the thermal front from $t_{0}$ to $t_{F i n}^{*}$ during the discharging process for different combinations of upper \& bottom baffles is shown in Fig. 11. By comparing case 1 (without upper baffle \& uniform orifice bottom baffle) and case 2 (uniform orifice upper \& bottom baffles), it can be noticed that the uniform upper baffle postpones the advancement of the thermocline region. The comparison between case 2 and case 3 (optimized upper baffle \& uniform orifice bottom baffle) clearly shows that the optimized upper baffle has a positive effect on flattening the thermal front during the discharging process, mainly because of the higher lateral velocity profiles induced by the larger orifices next to the wall (Fig. 10). This positive effect can be reflected by the higher discharging efficiency of case $3(0.50)$ than that of case $2(0.42)$ as indicated in Table 3 . Among all the tested cases, case 4 (optimized upper \& bottom baffles) has the smallest entering quantity of cold HTF at $t_{\text {Fin }}^{*}$ moment. The optimized bottom baffle forced the cold HTF toward the lateral walls in the bottom manifold before entering into the middle flow zone.

The charging, discharging and overall efficiencies for different combinations of upper \& bottom baffles are presented in Table 3 . Note that the $\eta_{\text {overall }}$ represents the overall efficiency of one cycle of fully charging/discharging processes. Not surprisingly, the combination of optimized upper \& bottom baffles provides the best performances. One interesting finding by comparing case 3 and 
case 4 is that the installation of optimized bottom baffle favors both the charging and the discharging efficiencies. This may be explained by the optimum velocity profile achieved by case 4 , i.e., negative parabolic shaped velocity profiles can be guaranteed for all three horizontal cutting surfaces ( $P 1, P 2$ and $P 3$ indicated in Fig. 10) by using the combination of optimized upper \& bottom baffles. Higher velocity near to the lateral walls would aide to overcome the frictional forces near to side wall, rendering flatter progress of thermal fronts inside the storage tank (Fig. 11).

By comparing case 2 and case 4 in Fig. 10, another important conclusion is that uniform velocity profile at horizontal surfaces doesn't necessarily lead to better thermocline performances. The results of this study support the finding of Wang et al. [2015] in that higher lateral velocities favor the temperature stratification inside the storage tank. But we go one step further because the optimal velocity profiles are deduced by using the proposed optimization algorithm, rather than empirically imposed.
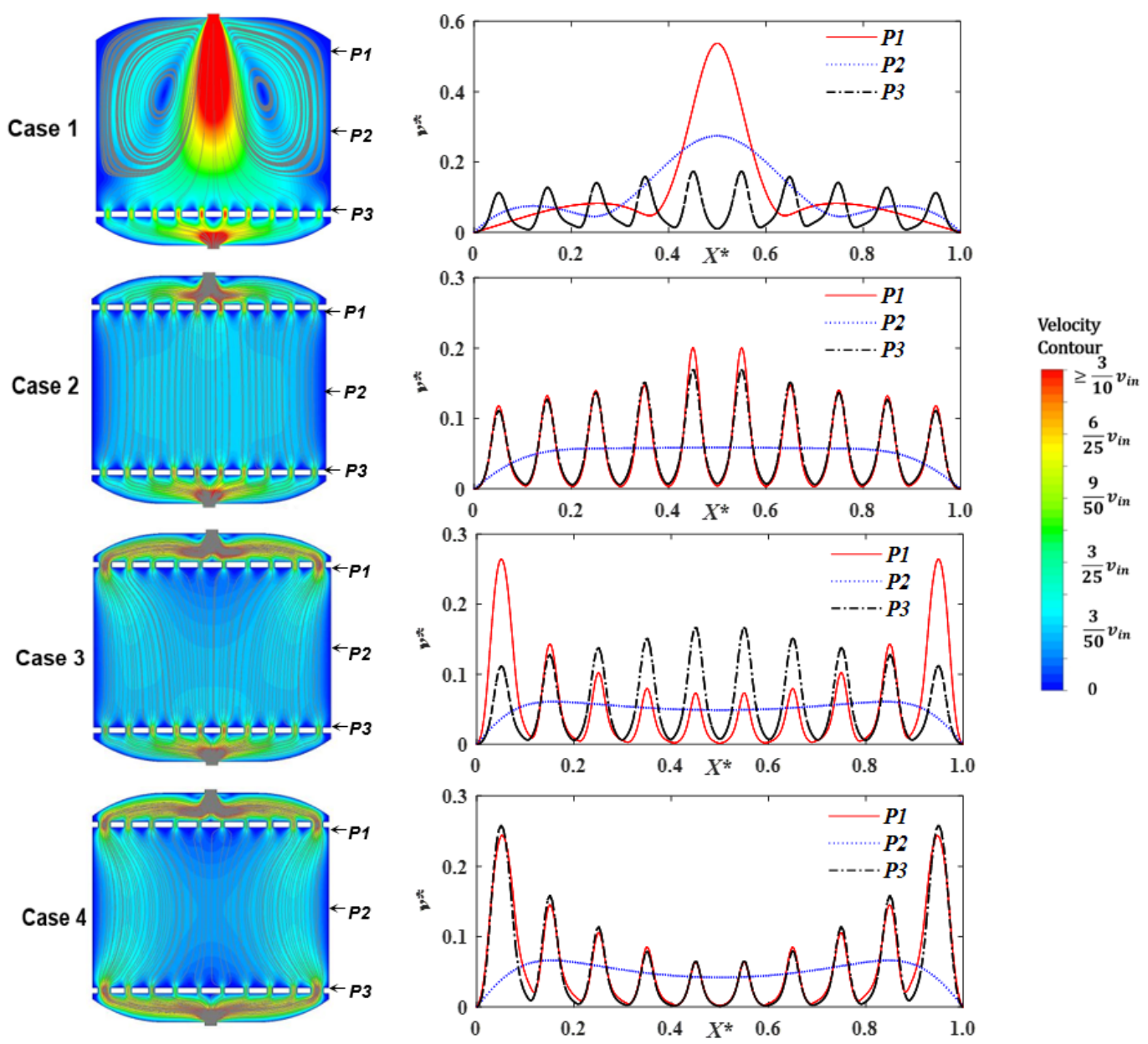

Figure 10. Terminal velocity profiles in the storage tank and at different height positions for different combination of upper $\&$ bottom baffles cases (charging process) 


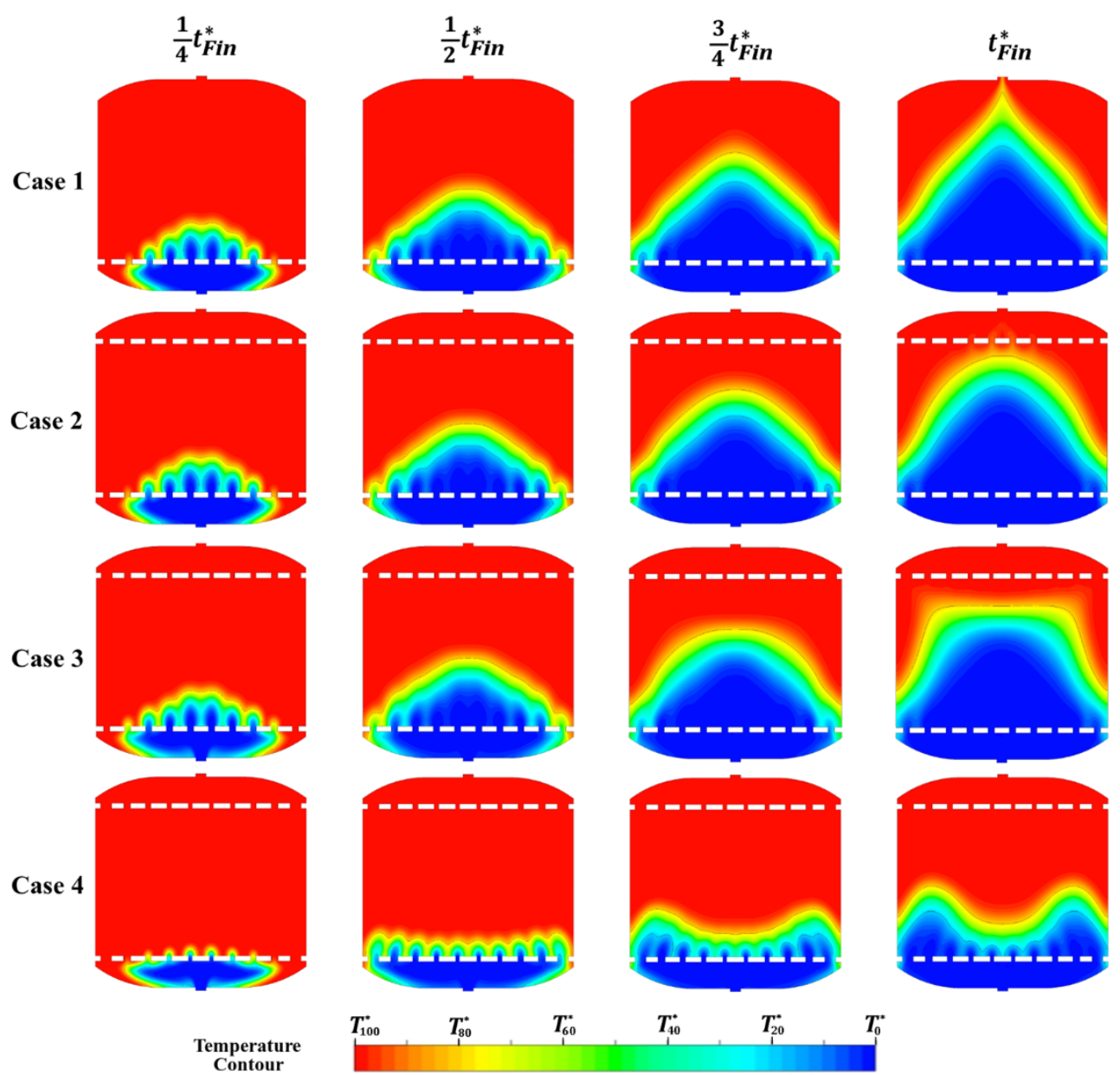

Figure II. Evolution of the temperature profiles in the storage tank from to to $t_{\text {Fin }}^{*}$ during the discharging process for different combination of upper $\&$ bottom baffles cases

Table 3. Charging, discharging and overall efficiencies for different combinations of upper \& bottom baffles

$\begin{array}{cccc}\text { Case } 1 & \text { Case } 2 & \text { Case } 3 & \text { Case } 4 \\ \text { ut upper baffle } & \text {-Uniform upper baffle } & \text {-Optimized upper baffle } & \text {-Optimized upper baffle }\end{array}$

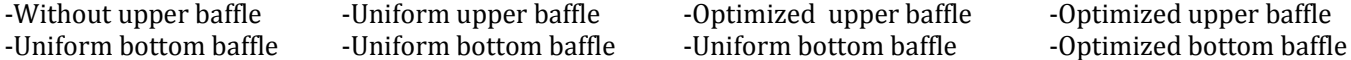

\begin{tabular}{ccccc} 
& -Uniform bottom baffle & -Uniform bottom baffle & -Uniform bottom baffle & -Optimized bottom baffle \\
\hline Charging & 0.17 & 0.41 & 0.48 & 0.54 \\
\hline Discharging & 0.25 & 0.42 & 0.50 & 0.55 \\
\hline Overall & 0.04 & 0.17 & 0.24 & 0.30 \\
\hline
\end{tabular}

\section{Effect of design parameters}

In this section, the effects of some design and operational parameters on the performances of the thermocline storage tank will be systematically evaluated, so as to test the robustness and effectiveness of the proposed optimization algorithm. These parameters include the Reynolds number $(R e)$, the aspect ratio $(H / L)$, the cone angle $(\theta)$, the number of orifices $(N)$ and the global porosity of the baffle $(\Phi)$. While one design variable is tested, other parameters are kept the same as those used for the benchmark study in section 3. Note that for simplification reason, only the 
upper baffle has been optimized during the charging process when uniform orifice bottom baffle is always used for this parametric study.

\subsection{Reynolds number ( $R e)$}

Controversy exists in the literature regarding the effect of $R e$ (or injected HTF flow-rate) on the temperature stratification inside the storage tank. Some researchers [Bayón and Rojas, 2013] reported that an increasing inlet velocity could lead to an increased discharging efficiency, a thinner thermocline region and a shorter discharging time. Others observed the opposite performance that a higher $R e$ would reduce the effective discharging efficiency and time [ $\mathrm{Wu}$ et al., 2014]. The quantitative relation between thermal performance and $R e$ was still undetermined.

In this study, Re numbers based on the width of the storage $\operatorname{tank} L$ (Eq. 21) from 10 to 200 have been tested, covering the most used range for thermocline storage tanks in CSP application.

$$
\operatorname{Re}_{\text {tank }}=\frac{\rho \bar{v}_{\text {tank }} L}{\mu}
$$

Note that the mean temperature between the hot and cold HTFs $(700 \mathrm{~K})$ is used to calculate the $\rho$ and $\mu$ values. The temperature profiles inside the storage tank at $t_{F i n}^{*}$ time at 4 different $R e_{\text {tank }}$ numbers $(10 ; 50 ; 100 ; 200)$ are shown in Fig. 12 . With the increasing value of $\operatorname{Re}_{\text {tank, }}$, the thermocline zone approaches more the bottom port because of the stronger inertial force. The thermal fronts also become less flat, confirming that higher $R e_{\text {tank }}$ disturbs the temperature stratification. When uniform orifice upper baffle is used, the thermocline region for $R e_{\text {tank }}=100$ or 200 has even reached the bottom port at $t_{F i n}^{*}$. A decreased trend of charging efficiency versus the increasing $R e$ was observed, as shown in Table 4 .

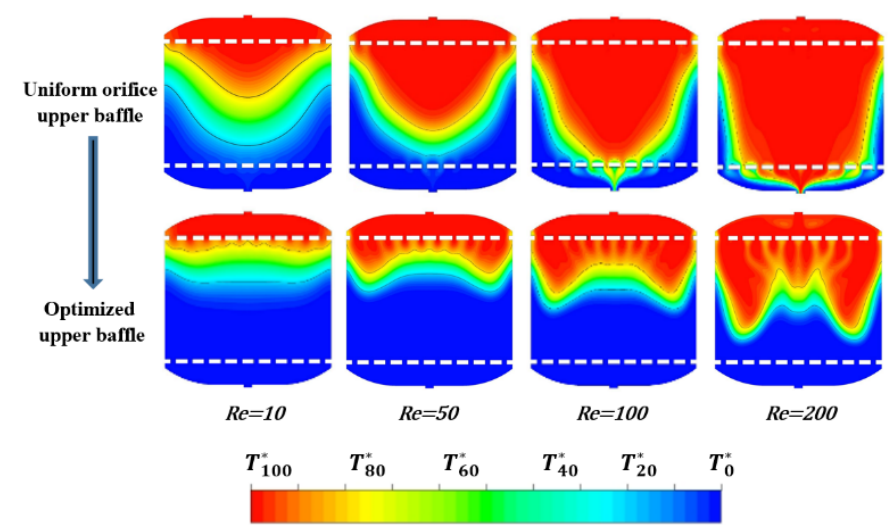

Figure 12. Effect of $R \mathbf{e}_{\text {tank }}$ on the temperature profile at $t_{F i n}^{*}$ time $\left(R e_{\text {tank }}=10 ; 50 ; 100 ; 200\right)$

By examining the values of performance indicators before and after optimization for each tested $R e_{\text {tank }}$ (Table 4 ), one can clearly observe that the $S^{*}$ value could be largely reduced while the values of $\varepsilon, \eta$ and $\sigma$ significantly augmented. When $R e$ is very small, the time for heat transfer between the hot and cold HTFs is longer, resulting in larger $S^{*}$ value and small $\sigma$ value. In this regard, the conduction may play an effective role of the heat transfer. But the higher the $R e_{t a n k}$, the double- 
1 hump shape of the thermal fronts at $t_{\text {Fin }}^{*}$ becomes more visible, as shown in Fig. 12. It is more 2 difficult to flatten out the irregular thermal fronts due to the stronger inertial force which is typically in response to convective fluid movement. Therefore, there may be a way to find a critical $R e$ in the

Table 4. Effect of $\operatorname{Re}_{\text {tank }}$ on the performance of the thermocline storage tank

\begin{tabular}{ccccccccccc}
\hline & \multicolumn{4}{c}{ Uniform orifice upper baffle } & \multicolumn{5}{c}{ Optimized orifice upper baffle } \\
\cline { 2 - 11 } & $t_{\text {Fin }}^{*}$ & $S^{*}$ & $\varepsilon$ & $\sigma$ & $\eta$ & $t_{\text {Fin }}^{*}$ & $S^{*}$ & $\varepsilon$ & $\sigma$ & $\eta$ \\
\hline 10 & 0.47 & 0.31 & 0.53 & 0.65 & 0.46 & 0.28 & 0.20 & 0.62 & 0.73 & 0.50 \\
$\mathbf{5 0}$ & 0.56 & 0.20 & 0.43 & 0.70 & 0.41 & 0.31 & 0.14 & 0.61 & 0.81 & 0.48 \\
100 & 0.72 & $>0.19$ & 0.37 & 0.71 & 0.39 & 0.41 & 0.14 & 0.53 & 0.83 & 0.44 \\
200 & 0.98 & $>0.13$ & 0.27 & 0.68 & 0.31 & 0.54 & 0.15 & 0.45 & 0.84 & 0.41 \\
\hline
\end{tabular}

\subsection{Aspect ratio}

The aspect ratio $(H / L)$ is also an important design parameter to consider. Three values of aspect ratio $(H / L=0.5 ; 1$ and 2$)$ have been tested and results are shown in Fig. 13 and Table 5.

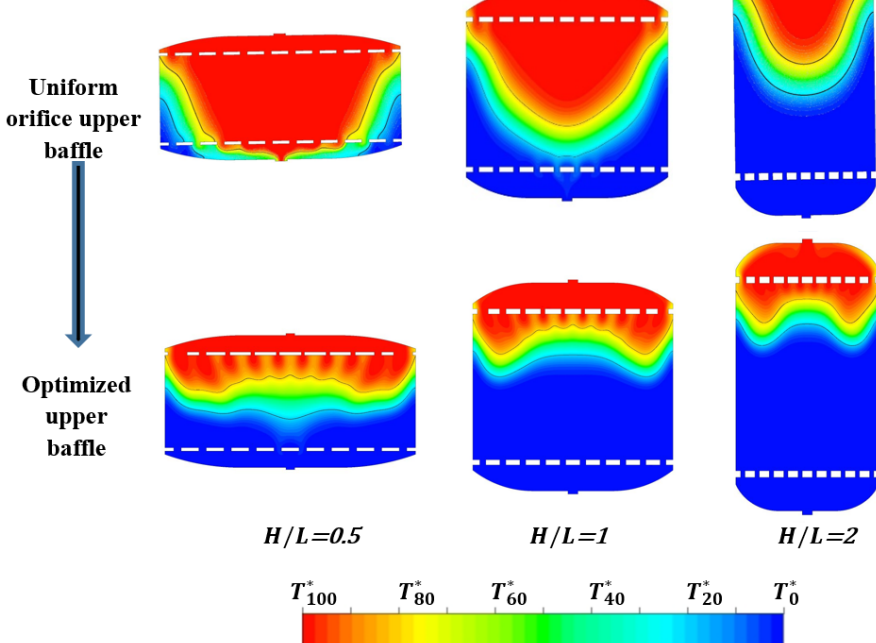

Figure 13. Effect of aspect ratio on the temperature profile at $t_{\text {Fin }}^{*}(H / L=0.5 ; I$ and 2$)$

Table 5. Effect of aspect ratio on the performance of the thermocline storage tank

\begin{tabular}{ccccccccccc}
\hline & \multicolumn{4}{c}{ Uniform orifice upper baffle } & \multicolumn{6}{c}{ Optimized orifice upper baffle } \\
\cline { 2 - 10 } & $t_{\text {Fin }}^{*}$ & $S^{*}$ & $\varepsilon$ & $\sigma$ & $\eta$ & $t_{\text {Fin }}^{*}$ & $S^{*}$ & $\varepsilon$ & $\sigma$ & $\eta$ \\
\hline $\mathbf{0 . 5}$ & 1.7 & $>0.23$ & 0.22 & 0.30 & 0.22 & 0.45 & 0.22 & 0.33 & 0.70 & 0.34 \\
$\mathbf{1}$ & 0.56 & 0.20 & 0.43 & 0.70 & 0.41 & 0.31 & 0.14 & 0.61 & 0.81 & 0.48 \\
$\mathbf{2}$ & 0.43 & 0.14 & 0.45 & 0.80 & 0.44 & 0.28 & 0.10 & 0.53 & 0.82 & 0.45 \\
\hline
\end{tabular}

Before optimization of the upper baffle, the thermocline zone shows a regular parabola shape. For small aspect ratio $(H / L=0.5)$, the height of the storage tank is not sufficient for the thermocline zone to develop. It spreads easily to the bottom manifold at $t_{\text {Fin }}^{*}$ time and influences greatly the 
$T_{\text {out }}^{*}$, indicated by the small value of $\varepsilon(0.22)$ in Table 5 . In this sense, a slender shape storage tank would be more advantageous for the propagation of the thermal fronts, as also reported by Mertens et al. [2014].

After optimizing the upper baffle, the surface area of thermocline zone $\left(S^{*}\right)$ for each $H / L$ value can be reduced to a great extent. The thermocline zones for all the tested cases stay above the bottom manifold at $t_{\text {Fin }}^{*}$ time, without interference to the $T_{o u t}^{*}$. Again the thermal performance of the charging process can be improved, indicated by the augmented values of various performance indicators listed in Table 5.

Regarding the $\varepsilon$ and $\eta$, better results are achieved for $H / L=1$ than $H / L=2$. This is because the optimization algorithm aims at minimizing $S^{*}$ the at $t_{\text {Fin }}^{*}$ time state while the thermocline area will further evolve due to the incomplete fully charging. This propagation of the thermocline zone at the lower half of the middle fluid zone is less controlled by the optimized upper baffle. The higher level of mixing between the hot and cold HTFs results a higher heat exchange, leading to lower values of the global performance indicators for $H / L=2$.

\subsection{Cone angle $\theta$}

Cone angle is a relatively new design parameter for thermocline storage tank when considering the truncated conical tank buried partially or totally underground so that the lateral earth would prevent the thermal deformation of the tank body during the cyclic operations. The upper diameter of truncated conical tank is expected to be larger than the bottom diameter (positive cone angle as shown in Fig. 14) so that larger proportion of the upper volume could be used to store the hot HTF, rendering a higher storage density [Zanganeh et al., 2015]. Three different cone angles $\left(\theta=-15^{\circ} ; 0^{\circ}\right.$; $+15^{\circ}$ ) have been tested and results are reported in Fig. 14 and Table 6.

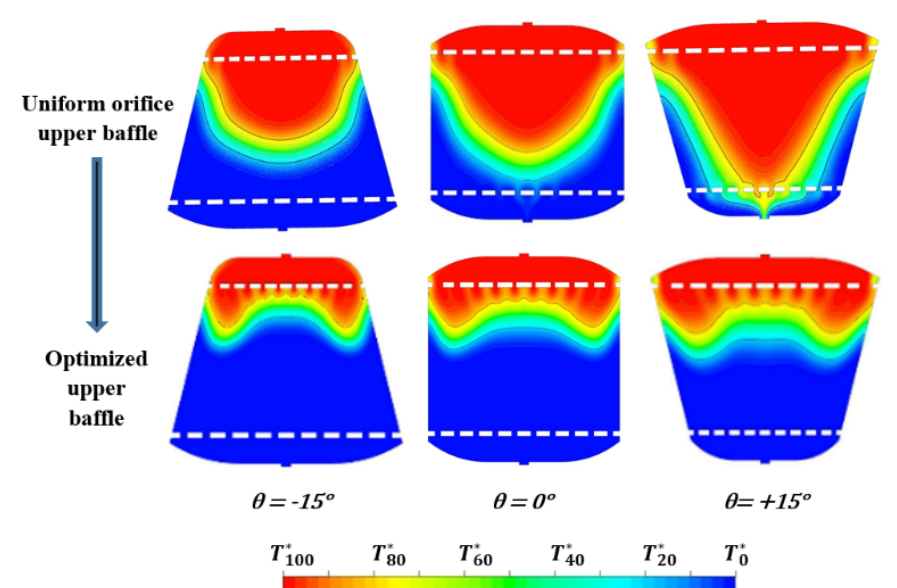

Figure 14. Effect of cone angle on the temperature profile at $t_{F i n}^{*}\left(\theta=-15^{\circ} ; 0^{\circ} ;+15^{\circ}\right)$

From Fig. 14 one may observe that the temperature profiles at $t_{\text {Fin }}^{*}$ time differ from the three $\theta$ values without optimization. The thermocline zone for $\theta=15^{\circ}$ case has already touched the bottom manifold because the converging shape makes the thermal fronts in the middle advance much faster 
than at the side. By optimizing the upper baffle, similar double-hump shape of the thermocline zone could be achieved. The results in Table 6 also show that conical shape with positive angle $\left(\theta=15^{\circ}\right)$ performs better than the negative angle $\left(\theta=-15^{\circ}\right)$ when optimized upper baffle is used. This is because its upper flow area is relatively larger than others, thus more effectively controlled by the optimized upper baffle. However, the bottom baffle should also be carefully designed for the discharging process to render an optimal overall efficiency.

Table 6. Effect of cone angle on the performance of the thermocline storage tank

\begin{tabular}{cccccccccccc}
\hline & \multicolumn{4}{c}{ Uniform orifice upper baffle } & \multicolumn{6}{c}{ Optimized orifice upper baffle } \\
\cline { 2 - 11 } & $t_{\text {Fin }}^{*}$ & $S^{*}$ & $\varepsilon$ & $\sigma$ & $\eta$ & $t_{\text {Fin }}^{*}$ & $S^{*}$ & $\varepsilon$ & $\sigma$ & $\eta$ \\
\hline $\mathbf{- 1 5}^{\circ}$ & 0.44 & 0.15 & 0.42 & 0.68 & 0.40 & 0.24 & 0.11 & 0.50 & 0.78 & 0.44 \\
$\mathbf{0}^{\circ}$ & 0.56 & 0.20 & 0.43 & 0.70 & 0.41 & 0.31 & 0.14 & 0.61 & 0.81 & 0.48 \\
$\mathbf{+ 1 5}^{\circ}$ & 0.76 & 0.21 & 0.42 & 0.70 & 0.41 & 0.41 & 0.16 & 0.65 & 0.81 & 0.50 \\
\hline
\end{tabular}

\subsection{Number of orifices $N$}

The number of orifices $(N)$ on the baffle is also an important design \& optimization factor since it determinates how many small sub-streams entering the middle flow zone could be produced. Comparative studies were performed with $N$ value of 6,10 and 20 , while the total porosity of the upper baffle was fixed at $\Phi=0.30$. Results for the uniform orifice baffle case and optimized baffle case are reported in Fig. 15 and Table 7.

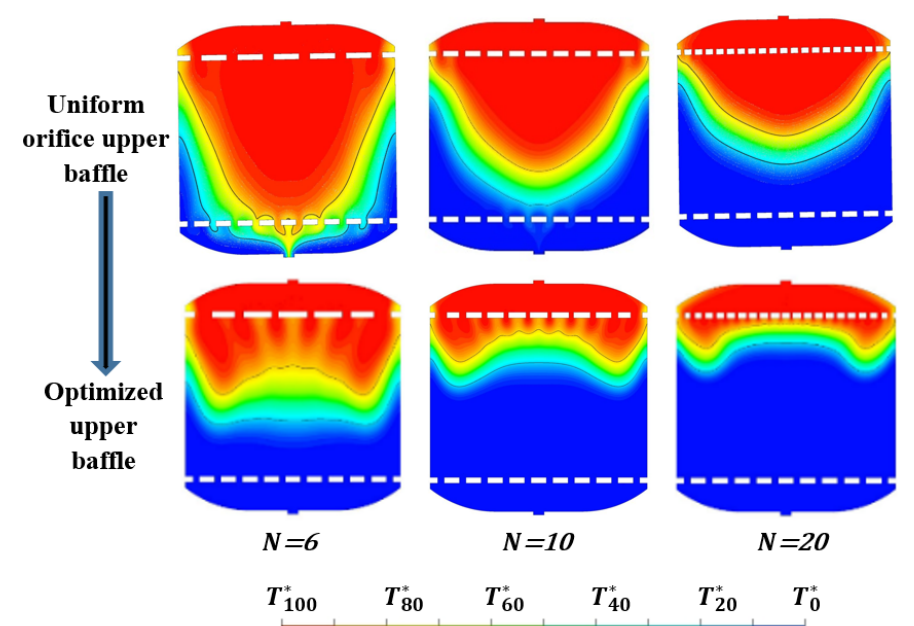

Figure I5. Effect of orifice number $(N)$ on the temperature profile at $t_{\text {Fin }}^{*}(N=6 ; 10 ; 20)$

Table 7. Effect of orifice number $\mathbf{N}$ on the performance of the thermocline storage tank

\begin{tabular}{ccccccccccc}
\hline & \multicolumn{4}{c}{ Uniform orifice upper baffle } & \multicolumn{5}{c}{ Optimized orifice upper baffle } \\
\cline { 2 - 10 } & $t_{\text {Fin }}^{*}$ & $S^{*}$ & $\varepsilon$ & $\sigma$ & $\eta$ & $t_{\text {Fin }}^{*}$ & $S^{*}$ & $\varepsilon$ & $\sigma$ & $\eta$ \\
\hline 6 & 0.79 & $>0.23$ & 0.41 & 0.68 & 0.40 & 0.49 & 0.20 & 0.59 & 0.80 & 0.48 \\
10 & 0.56 & 0.20 & 0.43 & 0.70 & 0.41 & 0.31 & 0.14 & 0.61 & 0.81 & 0.48 \\
20 & 0.45 & 0.15 & 0.48 & 0.73 & 0.44 & 0.24 & 0.11 & 0.60 & 0.80 & 0.48 \\
\hline
\end{tabular}


When uniform orifice upper baffle is used, the $S^{*}\left(t_{\text {Fin }}^{*}\right)$ value decreases with the increasing $N$. In fact, the width of orifice $(3 \mathrm{~mm})$ is much smaller for $N=20$ than that for $N=6(10 \mathrm{~mm})$, indicating higher flow resistance of the upper manifold that impedes the expansion of thermocline zone passing through. In particular, the mean local velocity traversed the upper baffle with 20 orifices must be larger than that with 6 orifices, which contributes to smaller amount of diffusive term versus the time accumulation. Vice versa, for small number of orifices, the hot front traversed together with much more accumulated diffusive term of the heat transfer [Baeten et al., 2016; Ansys theory Guide, 2019]. This results in the thicker thermocline zone and it even touches already the bottom port at $t_{\text {Fin }}^{*}$ moment. As a result, higher number of orifices having identical size is beneficial to maintain the temperature stratification.

When the optimized upper baffle is installed, the thermal fronts could be largely flattened for all three cases tested. Although the $S^{*}\left(t_{F i n}^{*}\right)$ value is reduced by half from $0.202(N=6)$ to 0.107 $(N=20)$, almost the same values of global performance indicators $(\varepsilon \approx 0.60 ; \eta \approx 0.48 ; \sigma \approx 0.80)$ could be achieved when using the optimized upper baffle. This implies that the proposed optimization algorithm is capable of achieving the optimum performance of the thermocline storage tank regardless of the number of orifices initially set up.

\subsection{Global porosity of baffle $(\Phi)$}

Three global porosity values $(\Phi=0.1 ; 0.3 ; 0.5)$ have been tested. The results obtained are shown in Fig. 16 and Table 8 and briefly commented as follows.

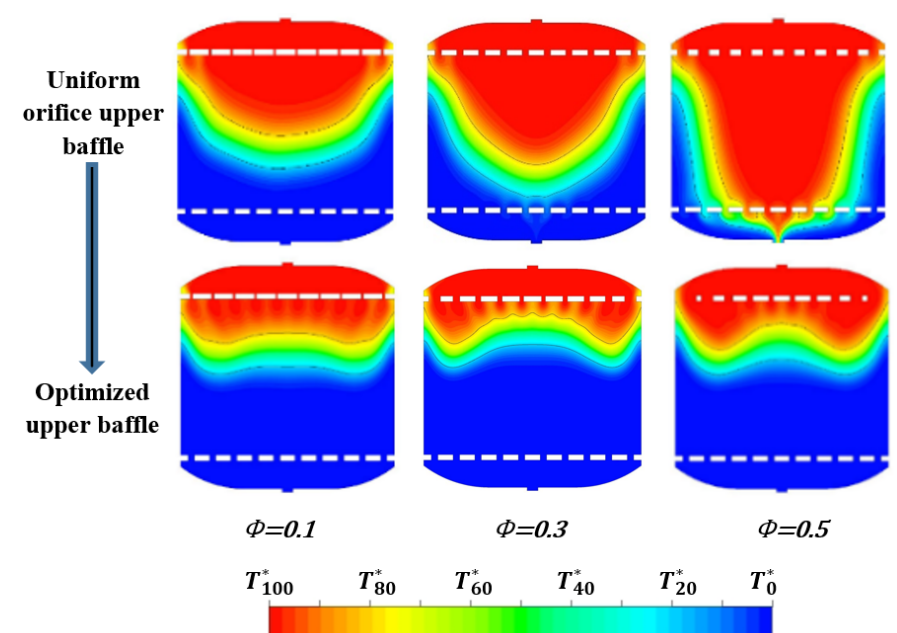

Figure 16. Effect of global porosity $(\Phi)$ on the temperature profile at $t_{\text {Fin }}^{*}$ time $(\Phi=0.1 ; 0.3 ; 0.5)$

In this paper, the global porosity is the proportional fluid length to whole length of the baffle $(L)$. Lower global porosity is beneficial to maintain the temperature stratification when uniform orifice upper baffle is used, again because of the higher flow resistance that impedes the natural propagation of the thermocline zone. On the other hand, the larger porosities may have more improving space in thermal performance. After optimization, similar shape of the thermocline zone can be reached at $t_{\text {Fin }}^{*}$, leading to smaller thermal performance difference of the storage tank. The larger porosities have more improved space for thermal performance, including $\varepsilon, \sigma, \eta$. 


\begin{tabular}{ccccccccccc}
\hline \multirow{\Phi}{\Phi}{} & \multicolumn{4}{c}{ Uniform orifice upper baffle } & \multicolumn{4}{c}{ Optimized orifice upper baffle } \\
\cline { 2 - 11 } & $t_{\text {Fin }}^{*}$ & $S^{*}$ & $\mathcal{E}$ & $\sigma$ & $\eta$ & $t_{\text {Fin }}^{*}$ & $S^{*}$ & $\mathcal{E}$ & $\sigma$ & $\eta$ \\
\hline $\mathbf{0 . 1}$ & 0.48 & 0.18 & 0.50 & 0.73 & 0.45 & 0.37 & 0.15 & 0.57 & 0.81 & 0.47 \\
$\mathbf{0 . 3}$ & 0.56 & 0.20 & 0.43 & 0.70 & 0.41 & 0.31 & 0.14 & 0.61 & 0.81 & 0.48 \\
$\mathbf{0 . 5}$ & 0.80 & $>0.22$ & 0.36 & 0.67 & 0.37 & 0.36 & 0.15 & 0.56 & 0.81 & 0.46 \\
\hline
\end{tabular}

\section{Conclusion and perspectives}

In the present study, the inlet/outlet manifolds of a thermocline storage tank are optimized, providing quasi-thermally piston flow inside the tank so as to maintain the temperature stratification during charging or discharging process. The design of upper and bottom manifolds is based on the insertion of perforated baffles. An original optimization algorithm is developed to determine the optimal orifice size distribution on the baffle, using a novel optimality criterion of equal passage time of hot front for every orifice. Based on the results obtained, main conclusions can now be summarized as follows:

- Uniform velocity distribution on horizontal cross-sections doesn't necessarily lead to the highest temperature stratification. Higher velocity near to the lateral walls aides to flatten the progress of thermal fronts, rendering better thermal performance of the thermocline storage tank.

- Equalizing the passage times of the hot front (optimality criterion) for different orifices can effectively minimize the surface area $\left(S^{*}\right)$ of the thermocline zone at $t_{\text {Fin }}^{*}$, leading to the significantly improved values of global performance indicators (tail factor, charging/discharging efficiency, capacity ratio).

- Optimizing one upper or bottom orifice baffle can be beneficial for both charging and discharging operations. The combination of the two optimized baffles provides the highest charging, discharging and overall efficiencies.

- The tail factor $(\varepsilon)$ can well indicate the performance of the thermocline storage tank. The values of $\varepsilon$ can provide additional information on the slope of the outlet HTF temperature curve, which may not be appropriately quantified by other commonly-used performance indicators.

- A series of parametric studies performed demonstrates that the proposed baffle insertion solution and the associated optimization algorithm are effective, efficient, robust and simple to implement. For all the tested cases, the performance improvement of the thermocline storage tank using our method is significant.

It should be noted that the efficiency of the optimization method depends largely on the correct simulation of the transient flow and temperature profiles during charging $\&$ discharging processes. In this study, we used constant density value at $700 \mathrm{~K}$ to represent the density variation between $600 \mathrm{~K}$ and $800 \mathrm{~K}$ to simplify the numerical model and to reduce the computational time. But a close 
look at the influence of the variable density values on the thermocline behaviors is in fact needed. Another important step is to extend the proposed optimization algorithm to $3 \mathrm{D}$, so as to tackle the flow distribution problem in real thermocline storage tanks with different shapes (rectangular, cylindrical or others). The validation by laboratory experiment of a thermocline storage tank equipped with or without optimized (orifice or annulus) upper \& bottom baffles is our on-going work.

In our study, one cycle of fully charging/discharging processes has been tested but in real-world operation of thermocline TES tanks, the cyclic effect has noticeable impact on the stored heat energy [Li et al., 2018] and the utilization rate [He et al., 2019]. Testing the robustness of the baffled distributor designs under (partial) cyclic operations is certainly an interesting topic to be investigated.

In the meantime, filling the storage tank with solid materials is now commonly considered in studies for CSP plants since it makes possible to the cost reduction of the TES system [Martin et al., 2018]. The optimization of thermocline behaviors at the presence of solid fillers by considering both the thermal diffusion the fluid-solid interactions is also the topic of our current work.

All these efforts help to provide generalized design guidelines for a possible upscaling from the laboratory to the industrial scale for real-world CSP application. In the meantime, the application fields of the energy-efficient thermocline units are rather vast and promising, and not limited to high temperature TES in CSP plants. Developing and integrating thermocline storage tanks with high energy efficiency, controllable and stable for long-time use and cost-effective for TES or energy recovery in other residential or industrial sectors [Chandra and Matuska, 2019; Han et al., 2009; Li, $2016]$ is the direction of our future work.

\section{Acknowledgement}

This work is supported by the French ANR within the project OPTICLINE (ANR-17-CE06-0013).

\section{References}

Afrin S, Kumar V, Bharathan D, Glatzmaier G, Ma Z. Computational analysis of a pipe flow distributor for a thermocline based thermal energy storage system. J Sol Energy Eng 2013;136:021010. https://doi.org//0.1115/1.4024927

Ahmed N, Elfeky K, Qaisrani, Mumtaz A, Wang Q. Numerical characterization of thermocline behaviour of combined sensible-latent heat storage tank using brick manganese rod structure impregnated with PCM capsules. Sol Energy 2019;180:243-256. https://doi.org/10.1016/j.solener.2019.01.001

Alva, G., Lin, Y., Fang, G. An overview of thermal energy storage systems. Energy 2018;144: 341-378. https://doi.org//0.1016/j.energy.2017.12.037 
Baeten, B., Confrey, T., Pecceu, S., Rogiers, F., \& Helsen, L. (2016). A validated model for mixing and buoyancy in stratified hot water storage tanks for use in building energy simulations. Appl Energy, I72, 21 7-229.

Bayón R, Rojas E. Simulation of thermocline storage for solar thermal power plants: From dimensionless results to prototypes and real-size tanks. Int J Heat Mass Transf 2013;60: 7I3-72I. https://doi.org/10.1016/j.ijheatmasstransfer.2013.01.047

Bruch A, Molina S, Esence T, Fourmigué J F, Couturier R. Experimental investigation of cycling behaviour of pilot-scale thermal oil packed-bed thermal storage system. Renew Energ 2017;103:277-285. https://doi.org/10.1016/j.renene.2016.11.029

Chandra Y, Matuska T. Stratification analysis of domestic hot water storage tanks: A comprehensive review. Energy Build 2019;187:1 10-131. https://doi.org/10.1016/j.enbuild.2019.01.052

De J, Reuter H. A review of performance modelling studies associated with open volumetric receiver CSP plant technology. Renew Sust Energ Rev 2018;82: 3848-3862. https://doi.org/10.1016/j.rser.2017.10.086

Ellingwood K, Mohammadi K, Powell K. A novel means to flexibly operate a hybrid concentrated solar power plant and improve operation during non-ideal direct normal irradiation conditions. Energy Convers Manag 2020;203:I | 2275. https://doi.org/10.1016/j.enconman.2019.112275

Esence T, Bruch A, Molina S, Stutz B, Fourmigué J. A review on experience feedback and numerical modeling of packed-bed thermal energy storage systems. Sol Energy 2017;153:628-654. https://doi.org/10.1016/j.solener.2017.03.032

FasquelleT, Falcoz, Q, Neveu, P, Hoffmann J. A temperature threshold evaluation for thermocline energy storage in concentrated solar power plants. Appl Energy 2018a; 212: 1153-1164. https://doi.org/10.1016/j.apenergy.2017.12.105

Fasquelle T, Falcoz Q, Neveu P. Numerical simulation of a 50MWe parabolic trough power plant integrating a thermocline storage tank. Energy Convers Manag 2018b;172:9-20. https://doi.org/10.1016/j.enconman.2018.07.006

Galione P, Pérez-Segarra CD, Rodríguez I, Torras S, Rigola J. Numerical evaluation of multi-layered solidPCM thermocline-like tanks as thermal energy storage systems for CSP applications. Energy Proc 20I5;69:83284 I https://doi.org/10.1016/j.egypro.2015.03.099

Geissbühler L, Kolman M, Zanganeh G, Haselbacher A, Steinfeld A. Analysis of industrial-scale hightemperature combined sensible/latent thermal energy storage. Appl Therm Eng 2016;101:657-668. https://doi.org/10.1016/j.applthermaleng.2015.12.031

Grirate H, Agalit H, Zari N, Elmchaouri A, Molina S, Couturier R. Experimental and numerical investigation of potential filler materials for thermal oil thermocline storage. Sol Energy 2016;131:260-274. https://doi.org/10.1016/j.solener.2016.02.035

Han Y, Wang R, Dai Y. Thermal stratification within the water tank. Renew Sust Energ Rev 2009; I3: I0I41026. https://doi.org//0.1016/j.rser.2008.03.001

He Z, Wang X, Du X, Amjad M, Yang L, Xu C. Experiments on comparative performance of water thermocline storage tank with and without encapsulated paraffin wax packed bed. Appl Therm Eng 2019; 147: 188-197. https://doi.org/10.1016/j.applthermaleng.2018.10.051

He, Z., Wang, X., Du, X., Xu, C., \& Yang, L. (2019). Cyclic characteristics of water thermocline storage tank with encapsulated PCM packed bed. Int J Heat Mass Transf, 139, $1077-1086$. https://doi.org/10.1016/j.ijheatmasstransfer.2019.05.093 
Hoffmann J, Fasquelle T, Goetz V, Py X. A thermocline thermal energy storage system with filler materials for concentrated solar power plants: Experimental data and numerical model sensitivity to different experimental tank scales. Appl Therm Eng 2016;100:753-76I. https://doi.org/10.1016/i.applthermaleng.2016.01.110

Keilany M, Milhé M, Bézian J, Falcoz Q, Flamant G. Experimental evaluation of vitrified waste as solid fillers used in thermocline thermal energy storage with parametric analysis. J Energy Storage 2020;29:10I285

Kim D, Ho Seok, Kim Y, Song C, Lee K, Choi J. Experimental studies of the discharge performance of singlemedium TES for CSP applications. Appl Therm Eng 2017; 127: $499-507$. https://doi.org// 0.1016/j.applthermaleng.2017.08.057

Kumar S, Singh P. A novel approach to manage temperature non-uniformity in minichannel heat sink by using intentional flow maldistribution. Appl Therm 2019.163:114403. https://doi.org/10.1016/j.applthermaleng.2019.114403

Li G. Sensible heat thermal storage energy and exergy performance evaluations. Renew Sust Energ Rev 2016;53:897-923. https://doi.org/10.1016/j.rser.2015.09.006

Li, M.-J., Qiu, Y., \& Li, M.-J. (20I8). Cyclic thermal performance analysis of a traditional Single-Layered and of a novel Multi-Layered Packed-Bed molten salt Thermocline Tank. Renew Energ II8. https://doi.org/10.1016/j.renene.2017.11.038

Luo L, Wei M, Fan Y, Flamant G. Heuristic shape optimization of baffled fluid distributor for uniform flow distribution. Chem Eng Sci 20 I5; I23:542-556. https://doi.org//0.10 I6/j.ces.2014.II.05 I

Martin C, Bonk A, Braun M, Odenthal C, Bauer T. Investigation of the long-term stability of quartzite and basalt for a potential use as filler materials for a molten-salt based thermocline storage concept. Sol Energy 2018; I7I: 827-840. https://doi.org/I0.1016/j.solener.2018.06.090

Mertens N, Alobaid F, Frigge L, Epple B. Dynamic simulation of integrated rock-bed thermocline storage for concentrated solar power. Sol Energy 2014; I 10: 830-842. https://doi.org/10.1016/j.solener.2014.10.02I

Milman O, Spalding D, Fedorov V. Steam condensation in parallel channels with nonuniform heat removal in different zones of heat-exchange surface. Int J Heat Mass Transf 2012; 55: 6054-6059. https://doi.org/10.1016/j.ijheatmasstransfer.2012.06.016

Modi A, Pérez-Segarra C. Thermocline thermal storage systems for concentrated solar power plants: Onedimensional numerical model and comparative analysis. Sol Energy 2014;100:84-89. https://doi.org/10.1016/j.solener.2013.11.033

Motte F, Falcoz Q, Veron E, Py X. Compatibility tests between Solar Salt and thermal storage ceramics from inorganic industrial wastes. Appl Energy 2015;155:14-22. https://doi.org//0.1016/j.apenergy.2015.05.074

Nandi B, Bandyopadhyay S, Banerjee R. Numerical modeling and analysis of dual medium thermocline thermal energy storage. J Energy Storage 2018;16: 218-230. https://doi.org/10.1016/j.est.2018.01.020

Nicolas L, Falcoz Q, Pham Minh D, Hoffmann JF, Meffre A, Nzihou A, Goetz V. Flexibility and robustness of a high-temperature air/ceramic thermocline heat storage pilot. J Energy Storage 2019;2I: 393-404. https://doi.org/10.1016/j.est.2018.11.034

Ortiz C, Valverde J, Chacartegui R, Perez-maqueda L, Giménez P. The Calcium-Looping $\left(\mathrm{CaCO}_{3} / \mathrm{CaO}\right)$ process for thermochemical energy storage in Concentrating Solar Power plants. Renew Sust Energ Rev 2019;1 1 3:109252. https://doi.org/10.1016/j.rser.2019.109252

Pelay U, Luo L, Fan Y, Stitou D, Castelain C. Integration of a thermochemical energy storage system in a Rankine cycle driven by concentrating solar power: Energy and exergy analyses. Energy 2019;167:498-510. https://doi.org/10.1016/j.energy.2018.10.163 
Pelay U, Luo L, Fan Y, Stitou D, Rood M. Thermal energy storage systems for concentrated solar power plants. Renew Sust Energ Rev 2017;79:82-100. https://doi.org/10.1016/j.rser.2017.03.139

Pizzolato A, Donato F, Verda V, Santarelli M, Sciacovelli A. CSP plants with thermocline thermal energy storage and integrated steam generator - Techno-economic modeling and design optimization. Energy 2017;139:231-246. https://doi.org/10.1016/j.energy.2017.07.160

Rodrigues F, Lemos M. Transient performance of a thermocline energy storage system using the two-energy equation model. Int J Heat Mass Transf 2020;150:I19323. https://doi.org/10.1016/j.ijheatmasstransfer.2020.119323

Sanz J, Nuñez F, Zaversky F. Benchmarking analysis of a novel thermocline hybrid thermal energy storage system using steelmaking slag pebbles as packed-bed filler material for central receiver applications. Sol Energy 2019;188:644-654. https://doi.org/10.1016/j.solener.2019.06.028

Vigneshwaran K, Sodhi G, Muthukumar P, Guha A, Senthilmurugan S. Experimental and numerical investigations on high temperature cast steel based sensible heat storage system. Appl Energy 2019;25 I:1 I3322. https://doi.org/10.1016/j.apenergy.2019.113322

Wang L, Yang Z, Duan Y. Influence of flow distribution on the thermal performance of dual-media thermocline energy storage systems. Appl Energy 2015;142:283-292. https://doi.org/10.1016/j.apenergy.2014.12.024

Wei M, Boutin G, Fan Y, Luo L. Numerical and experimental investigation on the realization of target flow distribution among parallel mini-channels. Chem Eng Res Des 2016;113:74-84. https://doi.org/10.1016/j.cherd.2016.06.026

Wei M, Fan Y, Luo L, Flamant G. Fluid flow distribution optimization for minimizing the peak temperature of a tubular solar receiver. Energy 2015a;91:663-677. https://doi.org/10.1016/j.energy.2015.08.072

Wei M, Fan Y, Luo L, Flamant G. CFD-based evolutionary algorithm for the realization of target fluid flow distribution among parallel channels. Chem Eng Res Des 2015b;100:341-352. https://doi.org//0.1016/j.cherd.2015.05.031

Wei M, Fan Y, Luo L, Flamant G. Design and optimization of baffled fluid distributor for realizing target flow distribution in a tubular solar receiver. Energy 2017;136:126-134. https://doi.org/10.1016/j.energy.2016.04.016

Wu M, Li M, Xu C, He Y, Tao W. The impact of concrete structure on the thermal performance of the dual-media thermocline thermal storage tank using concrete as the solid medium. Appl Energy 2014;1। 3:1363137|. https://doi.org//0.1016/j.apenergy.2013.08.044

Yin H, Ding J, Yang X. Experimental research on thermal characteristics of a hybrid thermocline heat storage system. Appl Therm Eng 2014;62:293-30I https://doi.org/10.1016/j.applthermaleng.2013.09.018

Zanganeh G, Pedretti A, Haselbacher A, Steinfeld A. Design of packed bed thermal energy storage systems for high-temperature industrial process heat. Appl Energy 2015;137:812-822. https://doi.org/10.1016/j.apenergy.2014.07.110

Zavattoni S, Geissbühler L, Barbato M, Zanganeh G, Haselbacher A, Steinfeld A. (20I7). High-temperature thermocline TES combining sensible and latent heat - CFD modeling and experimental validation. In: SolarPACES 2016 International conference, Abu Dhabi, UAE; 20I6. https://doi.org//0.1063/I.4984449

Zhang H, Baeyens J, Cáceres G, Degrève J, Lv Y. Thermal energy storage: Recent developments and practical aspects. Prog Energy Combust Sci 2016;53:1-40. https://doi.org/10.1016/j.pecs.2015.10.003

Zhao B, Cheng M, Liu C, Dai Z. Cyclic thermal characterization of a molten-salt packed-bed thermal energy storage for concentrating solar power. Appl Energy 2017; 195:761-773. https://doi.org/10.1016/j.apenergy.2017.03.110 


\section{List of Figures.}

Figure I. Schematic view of a 2D thermocline storage tank equipped with upper and bottom orifice baffles Figure 2. Definition of tail factor $\varepsilon$ for the charging (a) and the discharging (b) in a thermocline storage tank Figure 3. Schematic view on the evolution of the thermal front during the charging process Figure 4. Basic principle of the optimization algorithm for enlarging or reducing the size of an orifice Figure 5. Flow chart of the optimization algorithm

Figure 6. Grid independence test based on the dimensionless thermocline surface area $S^{*}\left(t_{\text {Fin }}^{*}\right)$

Figure 7. Dimensionless thermocline surface $S^{*}$ and standard deviation of passages times as a function of the optimization step

Figure 8. Comparison on the evolution of the temperature profiles in the storage tank from $t_{0}$ to $t_{F i n}^{*}$ during the charging process

Figure 9. Comparison on different performance indicators for the tested cases

Figure 10. Velocity profiles in the storage tank and at different height positions for different combination of upper \& bottom baffles cases (charging process)

Figure II. Evolution of the temperature profiles in the storage tank from t0 to $\boldsymbol{t}_{\text {Fin }}^{*}$ during the discharging process for different combination of upper \& bottom baffles cases

Figure 12. Effect of $R e_{\text {tank }}$ on the temperature profile at $t_{F i n}^{*}$ time $\left(R e_{\text {tank }}=10 ; 50 ; 100 ; 200\right)$

Figure 13. Effect of aspect ratio on the temperature profile at $t_{F i n}^{*}(H / L=0.5 ; I$ and 2$)$

Figure 14. Effect of cone angle on the temperature profile at $t_{F i n}^{*}\left(\theta=-15^{\circ} ; 0^{\circ} ;+15^{\circ}\right)$

Figure 15. Effect of orifice number $(N)$ on the temperature profile at $t_{F i n}^{*}(N=6 ; 10 ; 20)$

Figure 16. Effect of global porosity $(\Phi)$ on the temperature profile at $t_{F i n}^{*}$ time $(\Phi=0.1 ; 0.3 ; 0.5)$

\section{List of Tables}

Table I. Main geometric dimensions for the benchmark storage tank (unit: $\mathrm{mm}$ )

Table.2. Thermo-physical properties of the HTF [Hoffmann et al., 20I6]

Table 3. Charging, discharging and overall efficiencies for different combinations of upper \& bottom baffles

Table 4. Effect of $R e_{\text {tank }}$ on the performance of the thermocline storage tank

Table 5. Effect of aspect ratio on the performance of the thermocline storage tank

Table 6. Effect of cone angle on the performance of the thermocline storage tank

Table 7. Effect of orifice number $N$ on the performance of the thermocline storage tank

Table 8. Effect of global porosity $(\Phi)$ on the performance of the thermocline storage tank 